\title{
Airborne observations of far-infrared upwelling radiance in the Arctic
}

\author{
Quentin Libois $^{1}$, Liviu Ivanescu ${ }^{1,2}$, Jean-Pierre Blanchet ${ }^{1}$, Hannes Schulz ${ }^{3}$, Heiko Bozem ${ }^{4}$, W. Richard Leaitch ${ }^{5}$, \\ Julia Burkart $^{6}$, Jonathan P. D. Abbatt ${ }^{6}$, Andreas B. Herber ${ }^{3}$, Amir A. Aliabadi ${ }^{7}$, and Éric Girard ${ }^{1}$ \\ ${ }^{1}$ Department of Earth and Atmospheric Sciences, Université du Québec à Montréal, Montréal, Canada \\ ${ }^{2}$ Centre d'applications et de recherches en télédétection (CARTEL), Université de Sherbrooke, Sherbrooke, Canada \\ ${ }^{3}$ Alfred Wegener Institute, Helmholtz Center for Polar and Marine Research, Bremerhaven, Germany \\ ${ }^{4}$ Johannes Gutenberg University of Mainz, Institute for Atmospheric Physics, Mainz, Germany \\ ${ }^{5}$ Environment and Climate Change Canada, Toronto, Canada \\ ${ }^{6}$ Department of Chemistry, University of Toronto, Toronto, Canada \\ ${ }^{7}$ Atmospheric Innovations Research (AIR) Laboratory, School of Engineering, University of Guelph, Guelph, Canada
}

Correspondence to: Quentin Libois (quentin.libois@polytechnique.edu)

Received: 10 August 2016 - Published in Atmos. Chem. Phys. Discuss.: 26 September 2016

Revised: 29 November 2016 - Accepted: 2 December 2016 - Published: 20 December 2016

\begin{abstract}
The first airborne measurements of the FarInfraRed Radiometer (FIRR) were performed in April 2015 during the panarctic NETCARE campaign. Vertical profiles of spectral upwelling radiance in the range $8-50 \mu \mathrm{m}$ were measured in clear and cloudy conditions from the surface up to $6 \mathrm{~km}$. The clear sky profiles highlight the strong dependence of radiative fluxes to the temperature inversion typical of the Arctic. Measurements acquired for total column water vapour from 1.5 to $10.5 \mathrm{~mm}$ also underline the sensitivity of the far-infrared greenhouse effect to specific humidity. The cloudy cases show that optically thin ice clouds increase the cooling rate of the atmosphere, making them important pieces of the Arctic energy balance. One such cloud exhibited a very complex spatial structure, characterized by large horizontal heterogeneities at the kilometre scale. This emphasizes the difficulty of obtaining representative cloud observations with airborne measurements but also points out how challenging it is to model polar clouds radiative effects. These radiance measurements were successfully compared to simulations, suggesting that state-of-the-art radiative transfer models are suited to study the cold and dry Arctic atmosphere. Although FIRR in situ performances compare well to its laboratory performances, complementary simulations show that upgrading the FIRR radiometric resolution would greatly increase its sensitivity to atmospheric and cloud properties. Improved instrument temperature stability
\end{abstract}

in flight and expected technological progress should help meet this objective. The campaign overall highlights the potential for airborne far-infrared radiometry and constitutes a relevant reference for future similar studies dedicated to the Arctic and for the development of spaceborne instruments.

\section{Introduction}

Since the early days of weather satellites, remote sensing in the infrared (IR) has been used to study the vertical structure of the Earth atmosphere (e.g. Conrath et al., 1970). Most instruments currently deployed, such as the Moderate Resolution Imaging Spectroradiometer (MODIS; King et al., 2003), the Atmospheric Infrared Sounder (AIRS; Aumann et al., 2003) and the Infrared Atmospheric Sounding Interferometer (IASI; Blumstein et al., 2004), do not measure atmospheric radiation beyond approximately $15 \mu \mathrm{m}$, though, because sensing far-infrared radiation (FIR; $15 \mu \mathrm{m}<\lambda<100 \mu \mathrm{m}$ ) generally requires a different technology (Mlynczak et al., 2006). However, probing the atmosphere in the FIR could provide valuable information and complement current observations. The FIR range includes the strongly absorbing pure rotation band of water vapour and coincides with a maximum in the water vapour continuum strength (Shine et al., 2012). As such, it is especially promising for remote sensing 
of water vapour in the coldest regions of the atmosphere, that is the upper troposphere and the stratosphere (Rizzi et al., 2002; Shahabadi and Huang, 2014), and the polar regions in general (Turner and Mlawer, 2010; Blanchet et al., 2011; Palchetti et al., 2015). The emission maximum of Planck's function shifts towards the FIR with decreasing temperature, so that increasingly more energy is emitted from this spectral region (Merrelli and Turner, 2012) compared to the more widely used $6.7 \mu \mathrm{m}$ vibrational-rotational band (Susskind et al., 2003). Hence in cold atmospheres more than half of the radiation is lost to space from the FIR domain (Clough et al., 1992). The FIR signature of clouds also carries much information about cloud phase, optical thickness, particle effective size and particle shape for ice clouds (Rathke, 2002; Yang et al., 2003; Baran, 2007). This assessed sensitivity has recently stimulated the development of retrieval algorithms for ice cloud properties (e.g. Blanchard et al., 2009; Palchetti et al., 2016). Observing long-term changes in the FIR emission of Earth could eventually provide valuable insight into the physical processes underlying climate change (Huang et al., 2010).

As a consequence, in the last 3 decades a number of scientific teams have demonstrated the need for improved observation of the Earth in the FIR (e.g. Mlynczak et al., 2002; Harries et al., 2008). In the meantime, several FIR spectrometers were developed. The Atmospheric Emitted Radiance Interferometer (AERI; Knuteson et al., 2004) has been extensively used for atmospheric profiling and cloud remote sensing (Turner and Löhnert, 2014; Cox et al., 2014). The Far-InfraRed Spectroscopy of the Troposphere (FIRST; Mlynczak et al., 2006) and the Radiation Explorer in the Far-InfraRed - Prototype for Applications and Development (REFIR-PAD; Palchetti et al., 2006) were developed within the framework of the satellite projects Climate Absolute Radiance and Refractivity Observatory (CLARREO; Wielicki et al., 2013) and REFIR (Palchetti et al., 1999), respectively. These instruments primarily aim at better constraining the radiative budget of the atmosphere and have been operated from gondola and from the ground (Bianchini et al., 2011; Mlynczak et al., 2016). The Tropospheric Airborne Fourier Transform Spectrometer (TAFTS; Canas et al., 1997) has been used to explore the radiative properties of water vapour (Green et al., 2012; Fox et al., 2015) and to investigate the radiative properties of cirrus clouds (Cox et al., 2010). So far, all these spectrometers have been extensively used to improve the parameterization of the water vapour absorption lines and continuum in the FIR (Delamere et al., 2010; Liuzzi et al., 2014), in order to refine radiative transfer codes (Mlawer et al., 2012) and climate simulations (Turner et al., 2012).

Further understanding the radiative properties of the atmosphere in the FIR is of uttermost in the Arctic because proportionately more energy is emitted from cold regions at FIR wavelengths while at the same time lower water vapour column increases atmospheric transmittance (Clough et al.,
1992). Although FIR spectrometers have been used from the ground in Alaska and Northern Canada (Mariani et al., 2012; Fox et al., 2015), we are not aware of any such airborne measurements in the Arctic. The panarctic NETCARE (Network on Climate and Aerosols: Addressing Key Uncertainties in Remote Canadian Environments, http://www. netcare-project.ca) aircraft campaign, which took place in April 2015, attempted to fill this gap. This 4-week campaign investigated the radiative properties of the atmosphere in clear and cloudy conditions, with a stress on aerosols. These scientific flights offered the possibility to probe the atmosphere in situ, thus providing a valuable complement to the extensive ground observations performed at well instrumented sites such as Summit (e.g. ICECAPS project; Shupe et al., 2013) and Eureka (e.g. CANDAC network; Mariani et al., 2012). Altogether, these initiatives aim at refining our understanding of the radiative budget of the Arctic and the critical role clouds play in it, in the continuity of the seminal Surface Heat Budget of the Arctic Ocean (SHEBA) program (e.g. Shupe et al., 2006).

While most reported airborne FIR observations consist of constant altitude flights, vertical profiles of spectral radiance are very instructive to understand the vertical structure of the energy budget of the atmosphere (Mlynczak et al., 2011). For this reason, most measurements taken with the Far-InfraRed Radiometer (FIRR; Libois et al., 2016) during the campaign consisted of vertical profiles of upwelling radiance from the surface up to about $6 \mathrm{~km}$. The FIRR was developed as a technology demonstrator for the Thin Ice Clouds in Far-InfraRed Experiment (TICFIRE; Blanchet et al., 2011) satellite mission, the primary focus of which is on the water cycle in the Arctic, and ice clouds in particular. Like cirrus at midlatitudes (Cox et al., 2010; Maestri et al., 2014), ice clouds encountered in the Arctic significantly affect the atmosphere radiative budget in the FIR, especially because they can fill the whole troposphere (Grenier et al., 2009). In very dry conditions, they act as particularly efficient emitters that radiatively cool the atmosphere (Blanchet et al., 2011). Unlike the tropics, such ice cloud layers occur at any altitude, from the ground to the stratosphere (polar stratospheric clouds). Their radiative effect depends on their physical properties (Maestri, 2003; Maestri et al., 2005) but is also very dependent on moisture (Cox et al., 2015), making the interactions between water vapour and Arctic clouds particularly complex.

In the context of TICFIRE, there were four main reasons of flying the FIRR in the Arctic: (1) assessing the FIRR radiometric performances in airborne conditions meant to mimic as closely as possible satellite nadir observations; (2) validating radiative transfer simulations in the FIR for clear and cloudy Arctic conditions through radiative closure experiments; (3) verifying the spectral signature of clouds radiance in situ; (4) investigating the sensitivity of FIRR measurements to atmospheric characteristics and better understanding the radiative budget of the Arctic atmosphere. The FIRR measurements taken during the campaign are presented in 
Sect. 2, along with complementary observations relevant to the radiative properties of the Arctic atmosphere. Five case studies are then detailed in Sect. 3 and serve as a basis to assess FIRR performances in airborne conditions and explore its sensitivity to atmospheric conditions. The sensitivity to temperature, humidity and cloud properties is further investigated in Sect. 4 using radiative transfer simulations. Based on this unique experience, recommendations are provided for future operations of instruments similar to the FIRR in such airborne campaigns.

\section{Materials and methods}

\subsection{The NETCARE campaign}

The panarctic PAMARCMIP/NETCARE campaign (hereinafter NETCARE campaign) comprises many collaborators including the following institutions: Alfred Wegener Institute (AWI), University of Toronto, Environment and Climate Change Canada (ECCC) and more parties listed under the website. The campaign, which involved the two instrumented Basler BT-67 Polar 5 and Polar 6 aircraft (e.g. Ehrlich and Wendisch, 2015), started in Longyearbyen (Spitzbergen) on 5 April with 1-week delay due to harsh weather conditions. There, only one flight dedicated to calibration was performed. Then the aircraft flew across Station North (Greenland) and operated around Alert, Nunavut (Canada), from 7 to 9 April. Afterwards, they moved to Eureka, Nunavut (Canada), and stayed there until 17 April. They continued to Inuvik, Northwest Territories (Canada), where Polar 6 operated until 21 April, while Polar 5 headed towards Barrow (Alaska). No flights were performed with Polar 6 from 14 to 19 April due to cloudy conditions at Eureka and technical problems with the aircraft. The two aircraft had different scientific objectives, with Polar 5 mostly dedicated to sea ice studies and Polar 6 to aerosol and cloud studies. In the following, only Polar 6 operations are detailed, which consist of 10 scientific flights, amounting to $50 \mathrm{~h}$ of campaign flight time.

The NETCARE campaign aimed at better understanding aerosol transport into the Arctic in the early spring and its influence on ice cloud formation. One of the objectives was to characterize at the same time the microphysical and radiative properties of ice clouds, along with the nature of the aerosols, in order to further explore the conditions in which optically thin ice clouds form and how their microphysics depend on background aerosols. Many instruments were installed aboard Polar 6, including basic meteorology and radiation sensors, cloud microphysics instrumentation, particle counters, trace gas monitors and instruments for monitoring aerosol composition (e.g. Leaitch et al., 2016). Each flight was planned based on forecasts of clouds and transported pollution as well as the location of the A-Train satellite constellation (Stephens et al., 2002). The atmosphere was gen- erally probed vertically from the surface $(\sim 50 \mathrm{~m})$ to approximately $6000 \mathrm{~m}$ (or the other way round) in about $50 \mathrm{~min}$. To this end, the aircraft followed quasi-spirals of diameter $10 \mathrm{~km}$.

\subsection{In situ observations}

\subsubsection{The Far-InfraRed Radiometer}

The FIRR (Libois et al., 2016) uses a filter wheel to measure atmospheric radiation in nine spectral bands ranging from 8 to $50 \mu \mathrm{m}$ (Fig. 1). In this sense it is very similar to the Mars Climate Sounder (McCleese et al., 2007) and the Diviner Lunar Radiometer Experiment (Paige et al., 2010), which use uncooled thermal sensors to probe radiation in the FIR. The FIRR sensor is a 2-D array of uncooled microbolometers coated with gold black (Ngo Phong et al., 2015), and radiometric calibration is achieved with two reference blackbodies (BB) at distinct temperatures. The latter consist of cavities whose temperature and emissivity are well known, so that the radiance they emit is accurately estimated. During the NETCARE campaign, the FIRR was onboard Polar 6 and measured upwelling radiance directly through a $56 \mathrm{~cm}$ long vertical chimney. At the bottom of the chimney, a rolling door (Fig. 2) opened during the flight but remained closed otherwise to prevent dust or blowing snow from entering the instrument. Although the FIRR has a nominal field of view of $6^{\circ}$ corresponding to a 20 pixels diameter area on the sensor, here only a 15 pixel diameter area is used to avoid the small vignetting on the edges of the illuminated area. This corresponds to a field of view of $4.5^{\circ}$, which translates into a footprint of $7.8 \mathrm{~m}$ at a $100 \mathrm{~m}$ distance and $470 \mathrm{~m}$ at $6000 \mathrm{~m}$. Since the temperature aboard the unpressurized cabin quickly varied between approximately 0 and $15^{\circ} \mathrm{C}$, the ambient blackbody (ABB) was maintained at $15^{\circ} \mathrm{C}$, while the hot blackbody (HBB) was set to 45 or $50^{\circ} \mathrm{C}$. These correspond to $\mathrm{BB}$ nominal temperatures in flight but some experiments were performed with different $\mathrm{BB}$ temperatures depending on the environmental constraints, which is not problematic since the instrument's response is linear in this range of temperature (Libois et al., 2016). One FIRR measurement sequence lasts $210 \mathrm{~s}$, during which approximately $40 \mathrm{~s}$ are used to actually take measurements and $170 \mathrm{~s}$ are spent rotating the filter wheel and the scene selection mirror. A sequence consists of two calibration sequences (one on the $\mathrm{ABB}$ and one on the HBB) followed by three scene sequences, each sequence corresponding to one complete rotation of the filter wheel that measures all nine filters in approximately $40 \mathrm{~s}$. For each spectral band, 100 frames are acquired at $120 \mathrm{~Hz}$ and then averaged to provide a single 2-D image. One spectral measurement thus corresponds to a $0.8 \mathrm{~s}$ long acquisition and no supplementary temporal average is performed, highlighting the potential for fast scanning compared to interferometers that usually require averaging over several spectra to achieve comparably high performances (e.g. Mlynczak et al., 


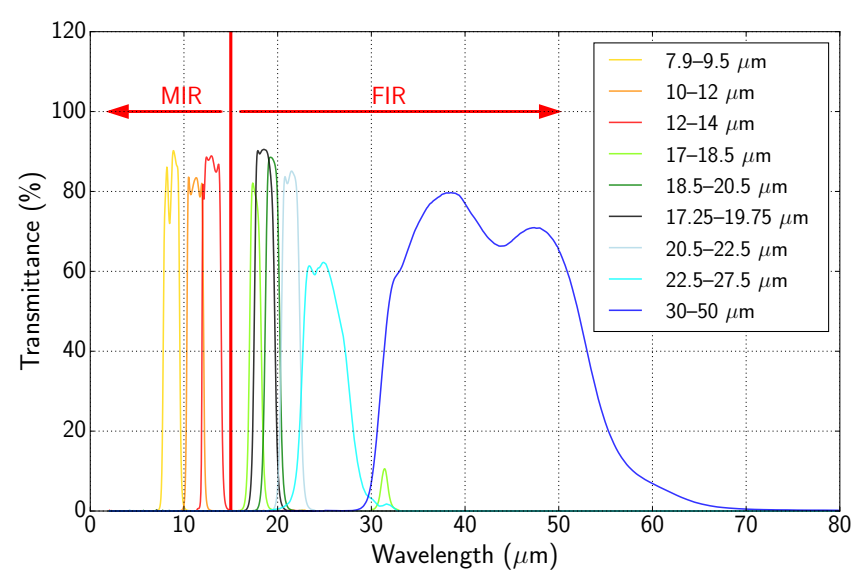

Figure 1. Spectral transmittances of the nine filters of the FIRR, whose band pass are indicated in the legend. Three filters cover the mid-infrared (MIR) and six are in the far-infrared (FIR).

2006). Such acquisition rate is essential when looking at heterogeneous or quickly moving targets, as is the case from an aircraft or satellite view. It is the main advantage of trading spectral resolution for higher signal levels. Note, though, that measurements in successive spectral bands are offset temporally, hence spatially, which has to be borne in mind at the stage of data interpretation. In this study, the FIRR is not used as an imager, and thus the data presented here correspond to averages over the selected area of 193 pixels. In this configuration, the radiometric resolution of the FIRR in laboratory conditions is essentially limited by detector noise and is about $0.015 \mathrm{~W} \mathrm{~m}^{-2} \mathrm{sr}^{-1}$. This corresponds to noise equivalent temperature differences of $0.1-0.35 \mathrm{~K}$ for the range of temperatures investigated in this study. The radiometric resolution is nearly constant for the seven bands ranging from 7.9 to $22.5 \mu \mathrm{m}$ because the absorptivity of the gold black coating is spectrally uniform and the filters all have similar maximum transmittances. It is approximately $30 \%$ less for the filters $22.5-27.5 \mu \mathrm{m}$ and $30-50 \mu \mathrm{m}$ because of limited filter transmittance for the band $22.5-27.5 \mu \mathrm{m}$ and reduced package window transmittance for the band 30-50 $\mu \mathrm{m}$. Such performances compare well with similar airborne spectroradiometers (e.g. Emery et al., 2014) and satellite sensors (e.g. MODIS).

A critical issue during the campaign was the temperature stability of the instrument in operation. Indeed, the first flights were characterized by excessively noisy measurements, especially in the $30-50 \mu \mathrm{m}$ channel. This noise was due to excessive air circulation within the chimney, cooling down very quickly the calibration enclosure and the filters. In particular, the metallic mesh filter $30-50 \mu \mathrm{m}$ has a very low thermal capacity and its temperature significantly changed in less than $1 \mathrm{~s}$, making the acquired data unusable. A floatzone silicone window was available that could be placed at the entrance of the instrument, but we decided not to use it since its limited transmittance of $30 \%$ in the FIR drastically

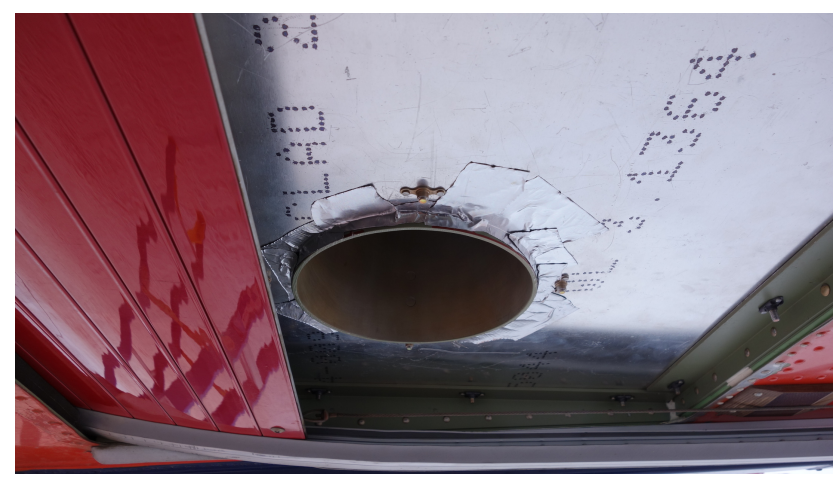

Figure 2. The rolling door at the bottom of the chimney through which FIRR takes measurements. The door is shown in optimal position for instrument stability, but nominal position is completely on the left. Flight direction is towards the left.

reduced signal level. This issue was fixed on 13 April by partially closing the rolling door in flight to prevent cold air flow from entering the inlet chimney, without impacting the field of view (Fig. 2). For previous flights, the calibration procedure detailed in Libois et al. (2016), which takes advantage of non illuminated pixels of the detector to remove the background signal, ensured good quality data for all bands except the $30-50 \mu \mathrm{m}$.

\subsubsection{Other measurements}

Polar 6 was equipped with a large set of sensors and instruments but only those relevant for the present study are mentioned below. Air temperature was recorded with an accuracy of $0.3 \mathrm{~K}$ by an AIMMS-20 manufactured by Aventech Research Inc. (Aliabadi et al., 2016). Trace gas $\mathrm{H}_{2} \mathrm{O}$ measurement was based on infrared absorption using a LI-7200 enclosed $\mathrm{CO}_{2} / \mathrm{H}_{2} \mathrm{O}$ analyzer from LI-COR Biosciences $\mathrm{GmbH}$. In situ calibrations during the flights were performed on a regular time interval of 15 to $30 \mathrm{~min}$ using a calibration gas with a known $\mathrm{H}_{2} \mathrm{O}$ concentration close to zero. The uncertainty for the measurement of $\mathrm{H}_{2} \mathrm{O}$ is $39.1 \mathrm{ppmv}$ or $2.5 \%$, whichever is greater. Broadband longwave (LW) radiation was measured with Kipp \& Zonen CGR-4 pyrgeometers installed below and above the aircraft (Ehrlich and Wendisch, 2015). These sensors have uncertainties of a few $\mathrm{W} \mathrm{m}^{-2}$. Nadir brightness temperature in the range 9.6-11.5 $\mu \mathrm{m}$ was measured by a Heitronics KT19.85 II with a field of view of $2^{\circ}$ and an accuracy of $0.5 \mathrm{~K}$. A number of probes also provided qualitative information about the presence of cloud particles. Total and liquid water content was measured with a Nevzorov probe (Korolev et al., 1998). An FSSP-300 particle probe was used to measure particle size distributions from 0.3 to $20 \mu \mathrm{m}$ from which cloud presence can be deduced (e.g. Ström et al., 2003). A PMS 2D-C imaging probe was supposed to detect larger particles, but the images were obscured due to a problem with the true air speed used in the image 
reconstruction, preventing accurate retrieval of particle size distribution. Practically, this sensor was mostly used to assess the presence of large cloud particles, but did not provide quantitative information about particle shape or size. A sun photometer specially designed for Polar 6 (SPTA model by Dr. Schulz \& Partner GmbH) was mounted on top of the aircraft and continuously tracked direct solar radiation in 10 spectral bands in the range $360-1060 \mathrm{~nm}$. From these spectral measurements, the atmospheric optical depth was deduced and further processed with the SDA method (O'Neill et al., 2003) to retrieve the contributions of the fine (aerosols) and coarse (mainly cloud and precipitation) mode components. In addition to these particle measurements, black carbon concentration was estimated to give an indication on the level of pollution of the investigated air masses. To this end, ambient air was sampled with an inlet mounted above the cockpit of Polar 6, and a single particle soot photometer (SP2 by Droplet Measurement Technologies, Boulder, Colorado) was used to evaluate the mass of individual refractive black carbon particles per volume of air (Schwarz et al., 2006), from which the mass for particles within the size range 75$700 \mathrm{~nm}$ was deduced. High-resolution nadir pictures taken at $15 \mathrm{~s}$ intervals also provided valuable information about the surface and the presence of clouds.

\subsection{Selected flights}

For the present study, five vertical profiles taken during five different flights were selected. These flights, whose trajectories are shown in Fig. 3, were performed near Alert $\left(82.5^{\circ} \mathrm{N}\right.$, $\left.62.3^{\circ} \mathrm{W}\right)$, Eureka $\left(80^{\circ} \mathrm{N}, 86.1^{\circ} \mathrm{W}\right)$ and Inuvik $\left(68.3^{\circ} \mathrm{N}\right.$, $\left.133.7^{\circ} \mathrm{W}\right)$ on $7,11,13,20$ and 21 April. All profiles were measured above snow-covered sea ice, which ensured that the surface was homogeneous contrary to flights performed above patches of snow and tundra or over areas of mixed sea ice and open water. All the investigated flights except 7 April were taken close to a track of the Cloud-Aerosol Lidar and Infrared Pathfinder Satellite Observations satellite (CALIPSO; Winker et al., 2003). Images taken by MODIS and the associated cloud products (Platnick et al., 2003) are also used to investigate cloud conditions above the aircraft. The five profiles were acquired in distinct atmospheric conditions, thus providing valuable samples of Arctic conditions in early spring. Flights from 7 to 13 April corresponded to typical conditions of the high Arctic cold season, with low temperatures and a pronounced inversion, while the conditions near Inuvik were more representative of subarctic spring, with near-melting temperatures at the surface and denser clouds typically found in the mid-latitudes. Some ice clouds were encountered on 7 April flight, but the more typical polar optically thin ice cloud was probed on 13 April near Eureka. The three other flights exhibited clear sky conditions below the aircraft.

\subsection{Radiative transfer simulations}

One objective of the study was to perform radiative closure experiments by comparing FIRR measurements with radiative transfer simulations based on thermodynamical and microphysical profiles recorded by the instruments aboard Polar 6. Here we used MODTRAN v.5.4 (Berk et al., 2005) to simulate upwelling radiance at flight level. MODTRAN uses absorption lines from HITRAN2013 and the MT-CKD 2.5 parameterization of the water vapour continuum (Clough et al., 2005) that proved reliable in the Arctic (Fox et al., 2015). The spectral surface emissivity of snow was taken from Feldman et al. (2014). Aerosols are approximated to the standard rural profile with a visibility of $23 \mathrm{~km}$, which is consistent with the presence of Arctic haze during the campaign. Multiple scattering is computed with DISORT (Stamnes et al., 1988) using 16 streams, and the band model is at $1 \mathrm{~cm}^{-1}$ spectral resolution. The model atmosphere has 75 levels from the surface to $30 \mathrm{~km}$, with a resolution of $0.1 \mathrm{~km}$ near the surface stretching to $0.7 \mathrm{~km}$ at the top. In addition to radiances, MODTRAN was used to compute Jacobians through finite differences (Garand et al., 2001).

Temperature and humidity profiles were interpolated from the in situ measurements up to the maximum flying altitude. Above, they were taken from the closest ERA-Interim reanalysis (Dee et al., 2011), the latter being offset to ensure vertical continuity. Ozone profiles for the whole column were also taken from ERA-Interim. Snow surface temperature was obtained from the KT19 observations assuming a uniform spectral response of the instrument and a spectrally flat surface emissivity of 0.995 in the range $9.6-11.5 \mu \mathrm{m}$. All simulated clouds in this study are ice clouds defined by their optical thickness $\tau$ and particle effective diameter $d_{\text {eff. Their single }}$ scattering properties are calculated after the parameterization of Yang et al. (2005) for cirrus clouds. Cloud geometrical characteristics were deduced from the combination of in situ observations. Optical thickness and effective cloud particle diameter were not directly measured. For 7 April, both quantities were tuned to minimize the deviation from measurements. For 13 April, the particle effective diameter was taken from DARDAR satellite product (Delanoë and Hogan, 2010) and simulations were performed for various optical depths.

\section{Results}

In this section, the FIRR radiometric performances are first analyzed based on experiments performed on the ground and during one flight. The five case studies are then analyzed in detail and the vertical profiles of radiance acquired in clear sky and cloudy conditions are compared to radiative transfer simulations. 

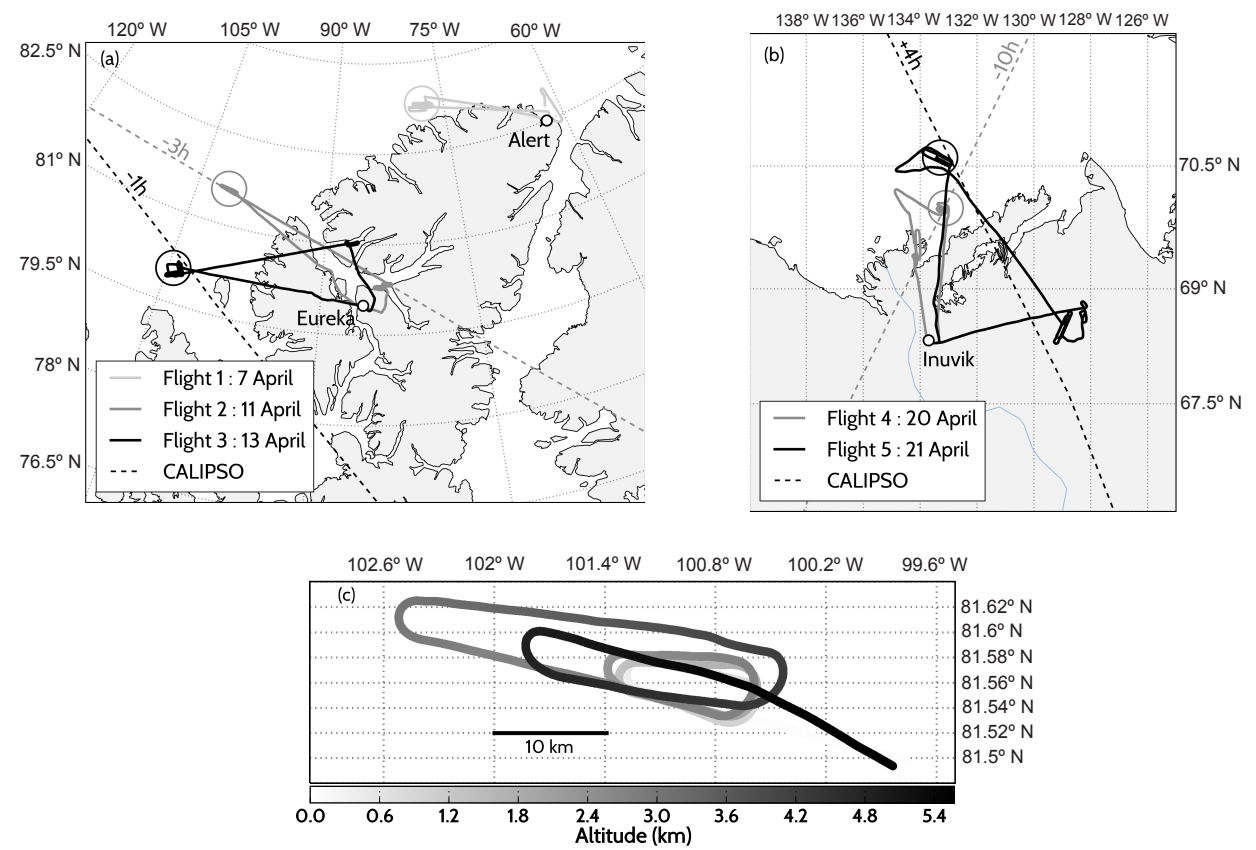

Figure 3. Selected flight trajectories around (a) Eureka and (b) Inuvik. The circles indicate where the detailed vertical profiles were performed. CALIPSO tracks are also shown and hours indicate how much earlier $(-)$ or later $(+)$ the satellite flew over. (c) Detailed spiral ascent for the 11 April flight.

\subsection{FIRR radiometric performances in airborne configuration}

The FIRR performances were investigated through laboratory and ground-based experiments by Libois et al. (2016). They estimated a radiometric resolution around $0.015 \mathrm{~W} \mathrm{~m}^{-2} \mathrm{sr}^{-1}$ and an absolute error of $0.02 \mathrm{~W} \mathrm{~m}^{-2} \mathrm{sr}^{-1}$, again slightly dependent on the channel considered. In airborne configuration, the environmental conditions were more demanding due to cold ambient temperature and quick background temperature variations. The FIRR performances for this specific setup are thus estimated from two experiments for which the environmental conditions were similar to nominal airborne operation, except the scene was more constant than in operation. Firstly, the brightness temperature of the snow surface below the aircraft was measured on Eureka runway on 12 April, while Polar 6 was parked without the propellers running. The ambient temperature was around $-32^{\circ} \mathrm{C}$, the $\mathrm{ABB}$ was at $-9.5^{\circ} \mathrm{C}$ and the $\mathrm{HBB}$ at $20^{\circ} \mathrm{C}$. Secondly, measurements taken on the closed rolling door just before landing on 11 April were analyzed. For this case, the ABB was at $15^{\circ} \mathrm{C}$ and the $\mathrm{HBB}$ at $45^{\circ} \mathrm{C}$.

The experiment on snow consisted of 10 consecutive measurement sequences covering $30 \mathrm{~min}$, so that 30 radiances were recorded for each spectral band. For all bands, the radiance increased continuously throughout the experiment, which was attributed to an increase of snow temperature. To remove this effect and focus on the resolution of the measurement only, the radiance series were first detrended, and the standard deviation of the residual was then computed. The latter does not exceed $0.012 \mathrm{~W} \mathrm{~m}^{-2} \mathrm{sr}^{-1}$. The experiment performed on the rolling door consisted of five consecutive sequences, and the standard deviation of the signal was larger, reaching $0.021 \mathrm{~W} \mathrm{~m}^{-2} \mathrm{sr}^{-1}$. Figure 4 a shows the corresponding brightness temperatures for both experiments, highlighting a temperature resolution around $0.1 \mathrm{~K}$ above snow and $0.2 \mathrm{~K}$ above the rolling door. Although the environmental conditions are slightly different in flight, these results provide a valuable reference and show that the installation of the instrument in the aircraft did not affect its performances.

To further investigate the reduced radiometric resolution observed in flight, Fig. $4 \mathrm{~b}$ shows the sequence of brightness temperatures recorded on the rolling door. A recurrent pattern is observed within a sequence of three consecutive measurements, with the first temperature generally larger than the following ones. We interpret this as the signature of fast and complex temperature variations of the skin temperature of the filters, which cannot be removed through the calibration procedure. We attempted to use the numerous temperature sensors embedded in the calibration enclosure and in the filter wheel to reconstruct the filters actual temperature, but this proved unsuccessful. Without any indication of whether any of the three consecutive points are the best, we simply conclude that this thermal instability results in an additive noise of approximate amplitude $0.2 \mathrm{~K}$ in worst conditions. This leaves room for future improvement of the instrument. The operational resolution of the FIRR nevertheless remains 

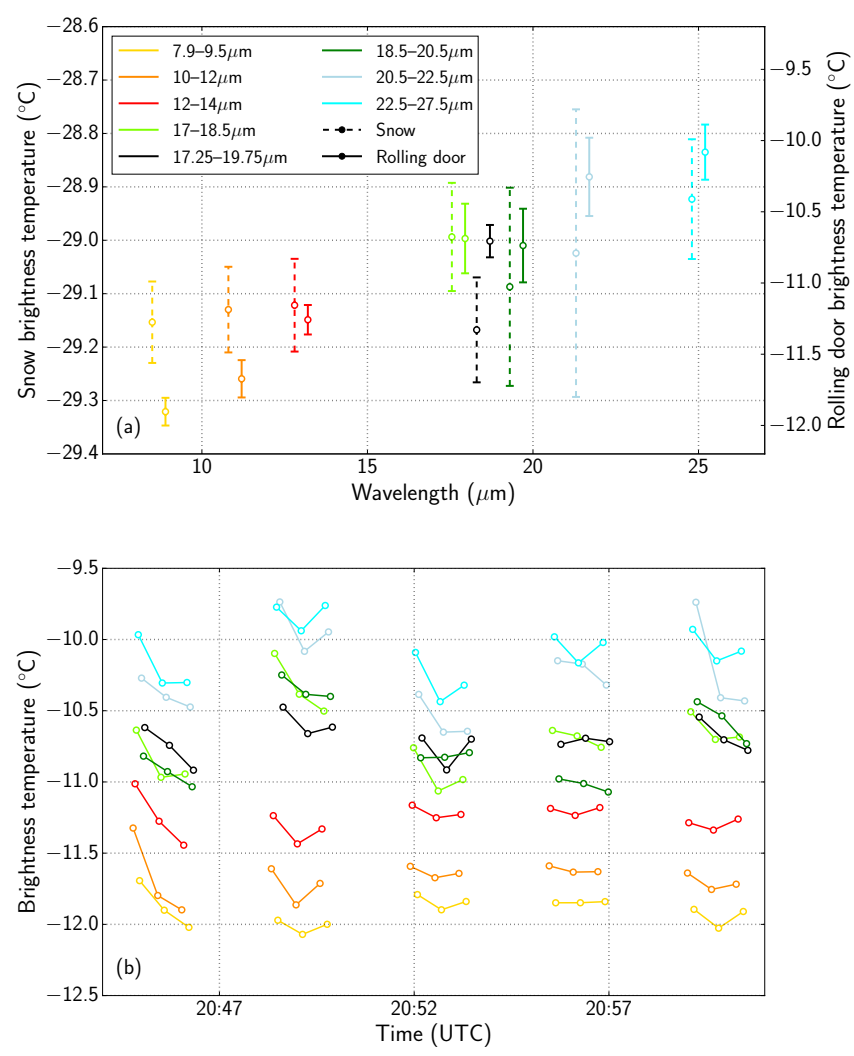

Figure 4. (a) Mean and standard deviations (error bars) of the detrended brightness temperatures along 10 sequences (i.e. 30 consecutive measurements) for measurements taken on snow on 12 April (15:10-15:42 UTC) and along 5 sequences on the rolling door on 11 April (21:45-22:00 UTC). For 12 April, $T_{\mathrm{HBB}}=20^{\circ} \mathrm{C}$ and $T_{\mathrm{ABB}}=-9.5^{\circ} \mathrm{C}$. For $11 \mathrm{April}, T_{\mathrm{HBB}}=45^{\circ} \mathrm{C}$ and $T_{\mathrm{ABB}}=15^{\circ} \mathrm{C}$. (b) Temporal evolution of brightness temperature for the five sequences acquired on the closed rolling door on 11 April. The 30$50 \mu \mathrm{m}$ band is not shown because it suffered from the temperature stability problem mentioned in Sect. 2.2.1.

well below $0.5 \mathrm{~K}$, which is still satisfactory and comparable to temperature measurements performed aboard Polar 6. This issue had not been noticed by Libois et al. (2016), most likely because in their study ambient temperature was closer to the internal temperature of the FIRR, limiting the range of filter temperature variations.

\subsection{Clear sky cases}

The profiles on 11, 20 and 21 April were all taken in clear sky conditions, but the total columns of water vapour were very different. These flights are specifically used to investigate the impact of temperature and humidity variations on the measured profiles of spectral radiances.

\subsubsection{April}

The ascent started at 19:02 and at 19:52 UTC Polar 6 reached the maximum altitude of $5.56 \mathrm{~km}$, where it stayed for $4 \mathrm{~min}$. On its way up it also levelled at $2.75 \mathrm{~km}$ for $7 \mathrm{~min}$. The surface temperature retrieved from the KT19 was $-32.6^{\circ} \mathrm{C}$ while a maximum of $-24^{\circ} \mathrm{C}$ was observed in the atmospheric temperature profile between 1 to $2 \mathrm{~km}$ (Fig. 5a). The whole atmosphere was undersaturated with respect to ice, except near the surface. The total column water vapour was $1.5 \mathrm{~mm}$, with $1.4 \mathrm{~mm}$ below $5.56 \mathrm{~km}$. No clouds were observed and the Aqua MODIS image taken at 18:45 UTC shows that no clouds were present above either. FIRR brightness temperature profiles show interesting features (Fig. 5b), with the temperature inversion more obvious for the longer wavelengths for which the atmosphere is more opaque. To further illustrate this differential sensitivity to the temperature profile, Fig. 6 shows the penetration depth of each channel as a function of altitude. The channels that penetrate the least are sensitive to the conditions closest below the aircraft. As expected, the brightness temperature in the highly transparent atmospheric window $(10-12 \mu \mathrm{m})$ is essentially constant with height since it is insensitive to the properties of the atmosphere. The slight increase of $0.5 \mathrm{~K}$ from the surface to the top is also observed in KT19 records and is probably the signature of surface temperature variations. The $17-18.5 \mu \mathrm{m}$ and $18.5-20.5 \mu \mathrm{m}$ profiles are very similar, implying relative redundancy between these two channels. The very distinct behaviours of window and FIR channels still result in nearly similar brightness temperatures at the top of the profile. This feature, typical of the Arctic, highlights the complexity of probing from space an atmosphere with a strong temperature inversion. The peaks in the shorter wavelengths channels around $4 \mathrm{~km}$ were found to visually correspond to variations of sea ice characteristics. They could be due to thinner and warmer sea ice or finer snow with higher emissivity (Chen et al., 2014). Since all individual measurements were used, the vertical resolution is close to $200 \mathrm{~m}$. However, the instability along three measurements is noticeable, e.g. for the $18.5-20.5 \mu \mathrm{m}$ channel below $2 \mathrm{~km}$. Besides this instrumental noise, part of the observed signal variation might be due to horizontal inhomogeneity, especially when the aircraft roll reaches up to $20^{\circ}$ in turns.

The vertical profile of upwelling broadband LW radiation also highlights the temperature inversion, with a maximum around $2 \mathrm{~km}$, similar to the FIR channels of the FIRR (Fig. 5c). LW fluxes have been simulated with MODTRAN and are also shown. The simulated and measured profiles are in close agreement above $2 \mathrm{~km}$, with a root mean square deviation (RMSD) of $0.35 \mathrm{~W} \mathrm{~m}^{-2}$. Such a value is consistent with the accuracy provided by the manufacturer and the absolute uncertainty of $2 \mathrm{~W} \mathrm{~m}^{-2}$ suggested by Marty (2003) for such sensors. This is very satisfactory for a sensor sensitive only up to $42 \mu \mathrm{m}$ while a significant part of the energy lies beyond, and considering that the calibration was done above $2{ }^{\circ} \mathrm{C}$. 

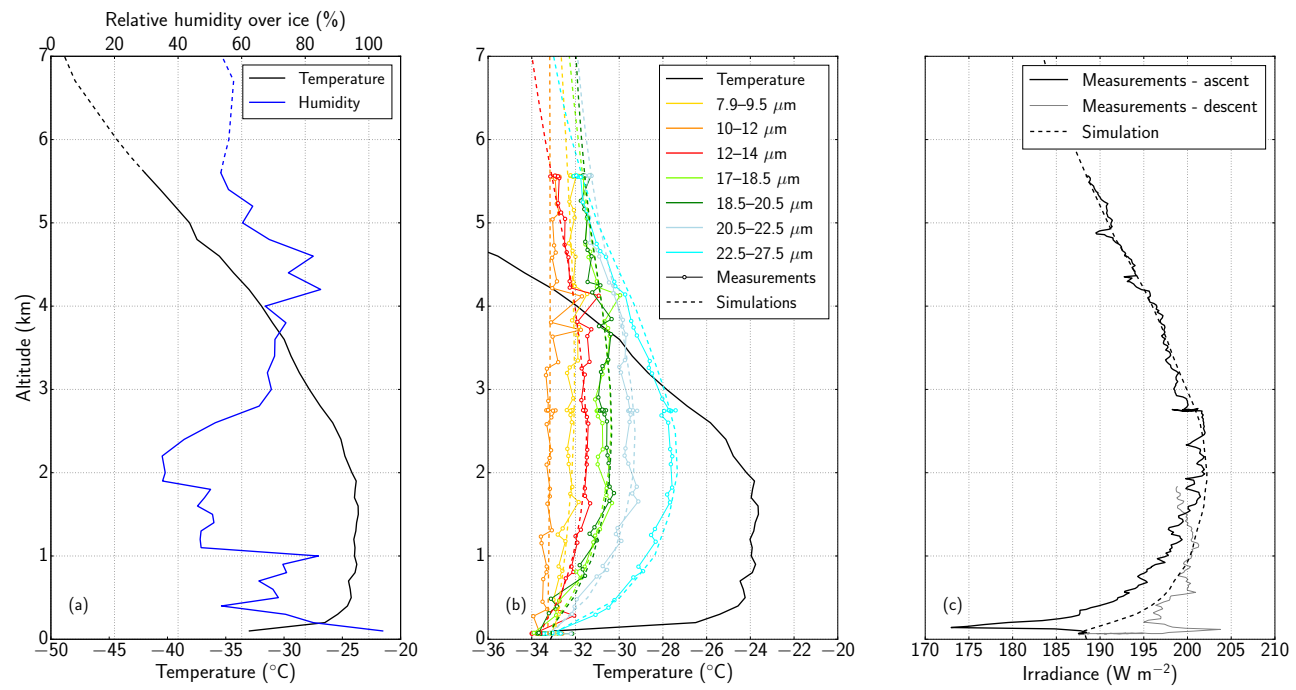

Figure 5. Vertical profiles of (a) temperature and relative humidity measured by in situ probes, (b) FIRR brightness temperatures and (c) upwelling broadband LW irradiance measured by the CGR-4 pyrgeometer for 11 April flight. The ascent portion correspond to the vertical profile and the descent portion shows the measurements taken $20 \mathrm{~min}$ prior to the ascent. The simulated FIRR brightness temperatures and LW irradiance are also shown. The 17.25-19.75 $\mu \mathrm{m}$ band is not shown because it overlaps with others. The dashed lines in panel (a) correspond to the ERA-Interim profiles used for the simulations above maximum flying altitude.

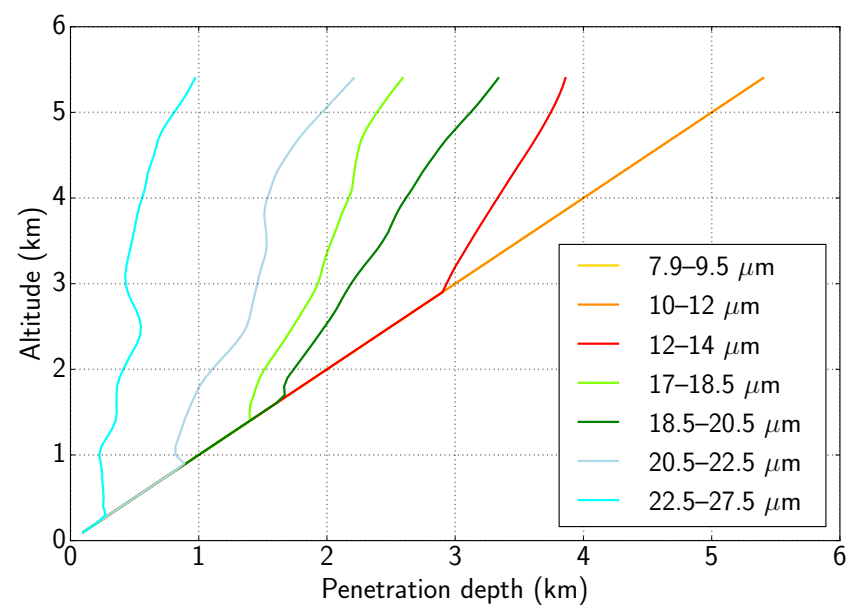

Figure 6. Penetration depth of each channel as a function of flying altitude for the 11 April flight. Penetration depth is defined as the downward distance from the plane such that the broadband transmittance in this channel reaches $75 \%$.

This agreement gives high confidence in the atmospheric profile measurements, as well as in the aerosols modelled in MODTRAN, because errors in aerosol profiles could result in discrepancies of several $\mathrm{W} \mathrm{m}^{-2}$ (Sauvage et al., 1999). Regarding the upper extrapolated part of the atmosphere, comparisons of measured and simulated downwelling LW fluxes (not shown) are also in reasonably good agreement, which gives confidence in the ERA-Interim fields. Close to the surface, measurements show an unexpected peaked minimum. Although the origin of this peak is not fully understood, we believe this is an instrumental artifact resulting from the strong temperature gradient near the surface and the sensor not being at thermal equilibrium (Ehrlich and Wendisch, 2015). This hypothesis is supported by the fact that data taken on the way down just before starting the ascent show a peak in the opposite direction.

MODTRAN was also used to simulate FIRR brightness temperatures (Fig. 5b). The measured profiles for all channels are well simulated, with a mean bias and RMSD below $0.2 \mathrm{~K}$. The agreement in the window bands confirms that no clouds were present below the aircraft. FIR simulations provide strong validation of the radiative transfer model, resulting in a satisfactory radiative closure in clear sky conditions. The spectral brightness temperatures are compared at the two altitudes where multiple measurements were taken. Figure 7 shows the average measured brightness temperatures at 2.75 and $5.56 \mathrm{~km}$ and the corresponding simulations. The spectral RMSD is below $0.15 \mathrm{~K}$ at both altitudes, which is very satisfying, given that MODTRAN user's manual suggests that the model accuracy is $1 \mathrm{~K}$. The variability of the measurements at each step is below $0.4 \mathrm{~K}$, which is consistent with the results of Fig. 4b. In addition, most deviations between observations and simulations are within the range of uncertainties due to uncertainties of the temperature and relative humidity measurements.

Overall, the simulations reproduce well the observations, which validates to some extent the radiative transfer code configuration and the implemented snow emissivity. However, such measurements can hardly be used for model improvement. As pointed out by Mlynczak et al. (2016), the inherent uncertainties related to the atmospheric measure- 


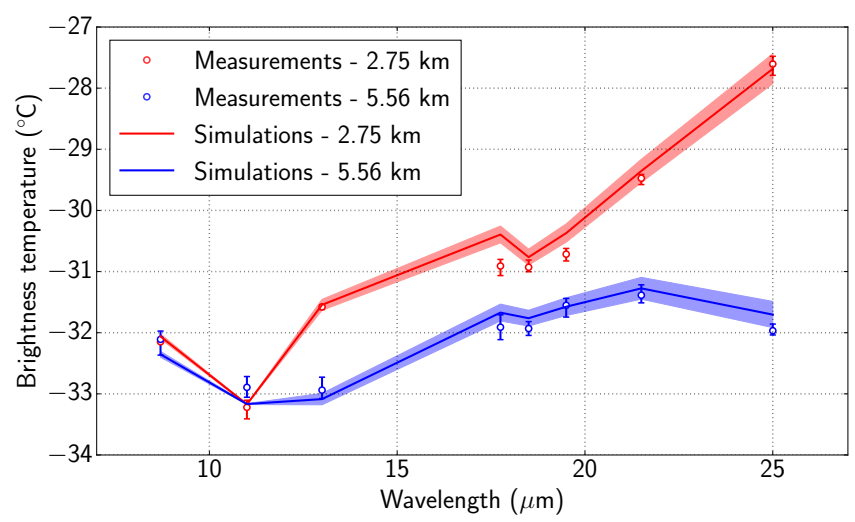

Figure 7. Measured and simulated spectral brightness temperatures at the two altitudes where Polar 6 levelled during 11 April flight. At both levels four consecutive measurements were taken. Their means and ranges are indicated by the circles and error bars, respectively. The shaded areas indicate the uncertainties in the simulations due to uncertainties on the measured temperature and relative humidity profiles, namely $0.3 \mathrm{~K}$ and $2.5 \%$.

ments and radiative transfer parameterization likely exceed the FIRR measurements uncertainties. Agreement is thus satisfactory and encouraging for the performances of the instrument but does not give further indications about the quality of the model inputs and parameterizations.

\subsubsection{0 and 21 April}

Both flights took place in the vicinity of Inuvik and showed relatively warm conditions and above freezing temperatures at the inversion level (Fig. 8a and c). The cloud probes suggested that no clouds were present, which is consistent with the relative humidity profiles. For 20 April flight, a moist layer typical of long range transport was found, which peaked near $2.5 \mathrm{~km}$ at about $85 \%$ humidity with respect to water. Above $3.5 \mathrm{~km}$, this layer was topped with drier air associated with weak air subsidence. Above $3.8 \mathrm{~km}$, the air was very whitish, and the FSSP-300 and sun photometer indicated increased level of aerosols. Likewise, SP2 measurements showed increasing amounts of black carbon with altitude, exceeding $0.1 \mu \mathrm{g} \mathrm{m}^{-3}$, which is indicative of a polluted air mass. Similar conditions were encountered on 21 April, except that the polluted layer was located above $2.6 \mathrm{~km}$, which again coincided with a drop of relative humidity. Sunphotometer data suggest the presence of high-altitude clouds with optical depth around 0.2 , but characterized by large variability. Those clouds were not accounted for in the simulations.

The vertical profiles of brightness temperatures are similar for both flights (Fig. 8b and d). Again, the window channels show very weak variations, which is characteristic of clear sky conditions. On the contrary, FIR channels are characterized by rapid variations near the surface and a larger
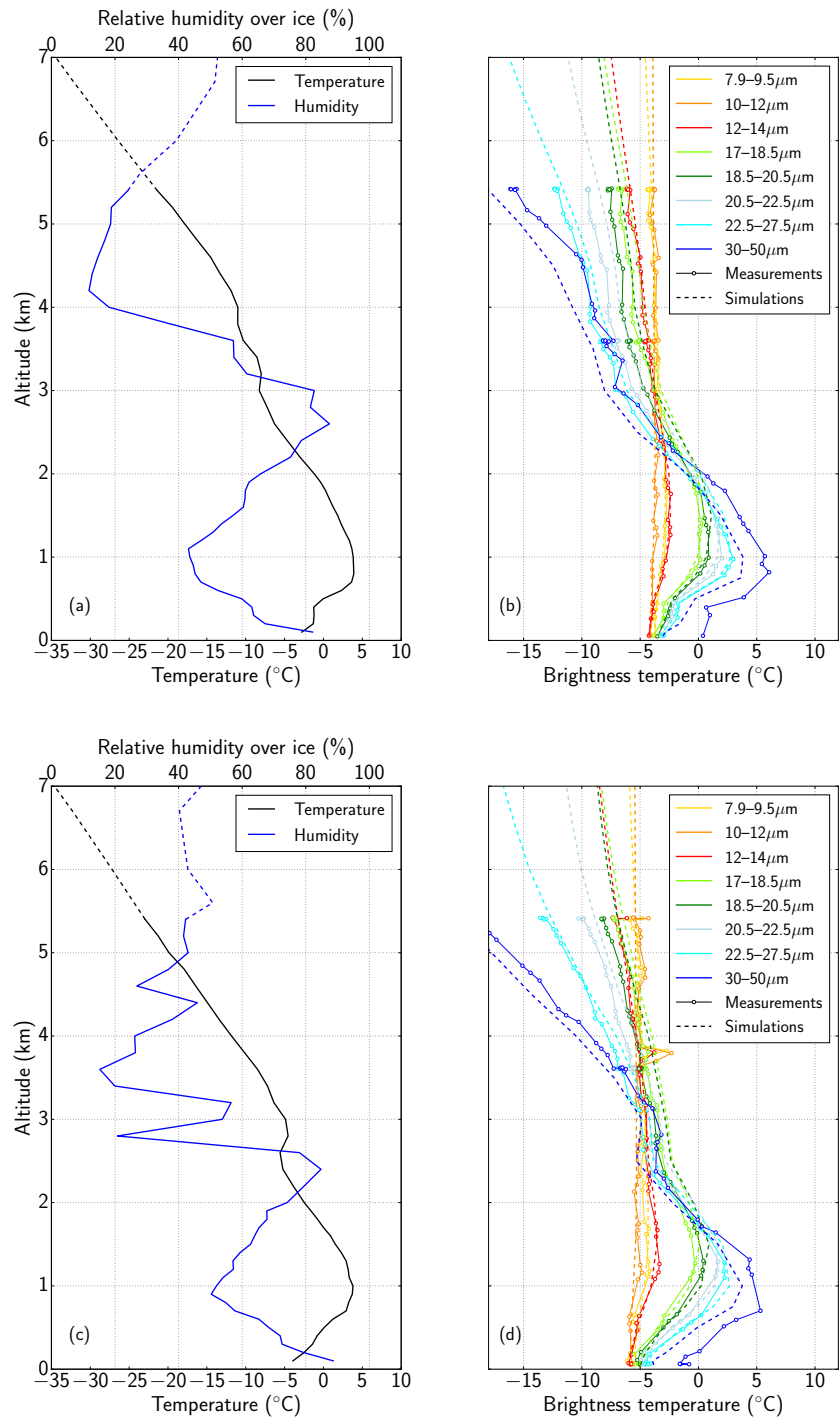

Figure 8. Vertical profiles of temperature and relative humidity for (a) 20 April and (c) 21 April flights. Measured and simulated FIRR brightness temperatures for (b) 20 April and (d) 21 April flights. The dashed lines in panels (a) and (c) correspond to the ERAInterim profiles used for the simulations above maximum flying altitude.

lapse rate at higher altitude compared to the 11 April flight. These features are due to a sharper temperature inversion and a reduced transparency of the atmosphere (the column water vapour below $5.4 \mathrm{~km}$ are 10.3 and $10.5 \mathrm{~mm}$, respectively). The difference between the conditions encountered on 11 and 20 April is further illustrated in Fig. 9. It shows the high spectral resolution brightness temperature simulated by MODTRAN at $6 \mathrm{~km}$ altitude for both flights and the corresponding simulated FIRR spectral signatures. This highlights the greater transparency of the atmosphere in the FIR for the 11 April. The peak observed at $3.8 \mathrm{~km}$ on 21 April corresponds to measurements over open water, as shown by a pic- 


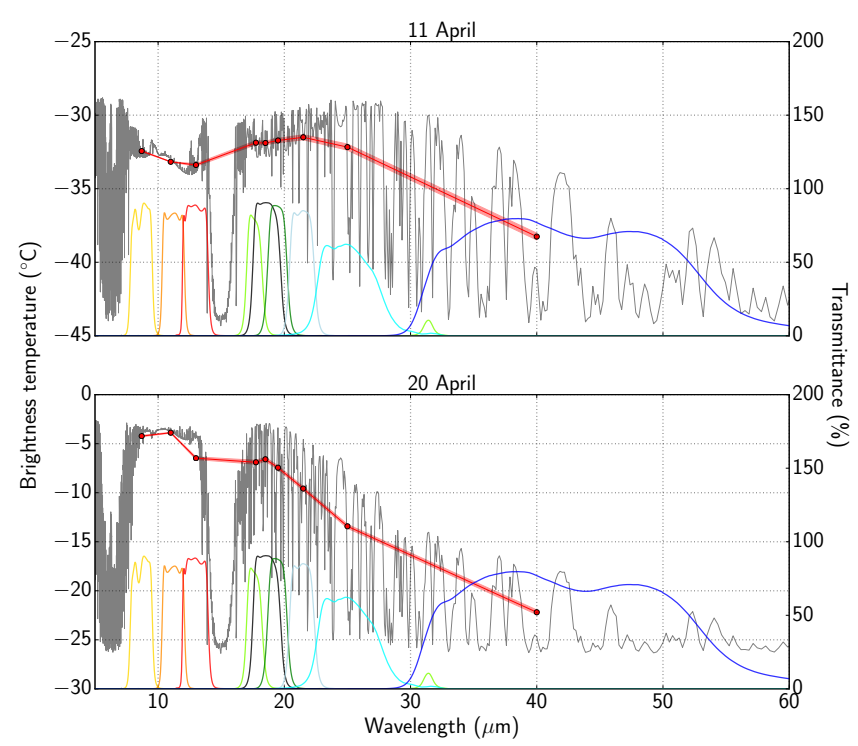

Figure 9. High spectral resolution brightness temperatures simulated with MODTRAN for the 11 and 20 April flights at $6 \mathrm{~km}$ altitude. FIRR filters transmittances are also shown, as well as the simulated FIRR spectral signatures. The red shaded areas indicate the uncertainties in the simulations due to uncertainties on the measured temperature and relative humidity profiles.

ture taken concomitantly (Fig. 10). More generally, since Polar 6 approximately flew at $75 \mathrm{~m} \mathrm{~s}^{-1}$, a single measurement of $0.8 \mathrm{~s}$ spanned $60 \mathrm{~m}$ at the surface. Similarly, a typical roll of $10^{\circ}$ during the spiral corresponds to $1 \mathrm{~km}$ deviation at the surface when flying at $6 \mathrm{~km}$. This could generate noise if the surface was not homogeneous at this scale, which was the case at the interface between the sea ice and open water.

The simulated brightness temperatures in the atmospheric window are in good agreement with observations, but deviations exceeding measurement uncertainties are found in the FIR channels for the upper part of the profile. The largest discrepancies are obtained in the $30-50 \mu \mathrm{m}$ band, with measurements being approximately $1.5 \mathrm{~K}$ warmer than the simulations. In fact, the air transmittance in this channel is so low that a significant part of the signal comes from the air contained in the $56 \mathrm{~cm}$ long chimney just below the instrument rather than from the atmosphere below. This artifact was noticed by Mlynczak et al. (2016). Using their correction (Eq. 1), we find that air at $-5^{\circ} \mathrm{C}$ and $50 \%$ relative humidity in the chimney can increase the apparent brightness temperature at $5 \mathrm{~km}$ altitude by $1.5 \mathrm{~K}$ in the $30-50 \mu \mathrm{m}$ band, while the deviation does not exceed $0.3 \mathrm{~K}$ for the other channels. For this reason, the data in the $30-50 \mu \mathrm{m}$ band are not reliable and are not shown in the rest of the paper. This is not critical in this study because at the flying altitude this band essentially probes local temperature. On the contrary, it is expected to be very valuable from a satellite view, where it should provide information about water vapour and clouds at the very top of the troposphere. The consistent positive bias of the simulations in the other FIR channels is more puzzling, especially because it is observed in both flights. Several factors could explain such discrepancies. Inaccuracies in the water vapour continuum are ruled out because recent studies have shown uncertainties below 10\% (Liuzzi et al., 2014; Fox et al., 2015), largely insufficient to explain such differences. Errors in water vapour measurements are also unlikely because independent measurements taken by distinct instruments aboard Polar 6 show differences less than $20 \%$, while only an increase larger than $50 \%$ could explain the observed differences. In addition, water vapour measurements along track did not show significant variability, so that spatial variability of water vapour can be ruled out. Only the incursion of a wet air mass below the aircraft before the end of the ascent could explain such a discrepancy between observations and simulations. In such case the water vapour profile used in the simulation would not correspond to the actual profile at the time of the measurement, but this is unlikely given that it was observed on two different flights. Adding an optically thin cloud between 6 and $9 \mathrm{~km}$ altitude did not improve the simulations either. Given the verified accuracy of the FIRR, we hypothesize that the differences are the consequence of the observed haze layer. This is in line with the significant radiative signature in the IR shown by Ritter et al. (2005) for similar aerosol optical depths as those experienced in these two flights. The fact that the window channels are not impacted remains unanswered, though. This might be due to the specific nature of the wet aerosols forming the haze layer, which should have a signature similar to water vapour in the FIR. This question is left to future work, where hyperspectral measurements would certainly help investigating the detailed response. It should nevertheless be borne in mind that in these particular cases the greenhouse effect is underestimated in MODTRAN simulations, which can lead to significant deviations on the atmospheric and surface energy budgets.

\subsection{Cloudy cases}

Flights performed on 7 and 13 April are used to assess the radiative impact of optically thin ice clouds in the FIR. They also highlight the difficulty to compare in situ observations to radiative transfer simulations due to high variability of the cloud microphysics.

\subsubsection{April}

During this flight west of Alert, singular atmospheric conditions were encountered. Near the surface, a saturated layer was found up to $1.1 \mathrm{~km}$ where a cloud was present, as detected by the Nevzorov and 2D-C probes. Another cloud was found above $4 \mathrm{~km}$, which extended up to the maximum flying altitude of $6 \mathrm{~km}$. In between, the atmosphere was very dry. The temperature profile had a complex signature near the surface, where a double temperature inversion was observed 


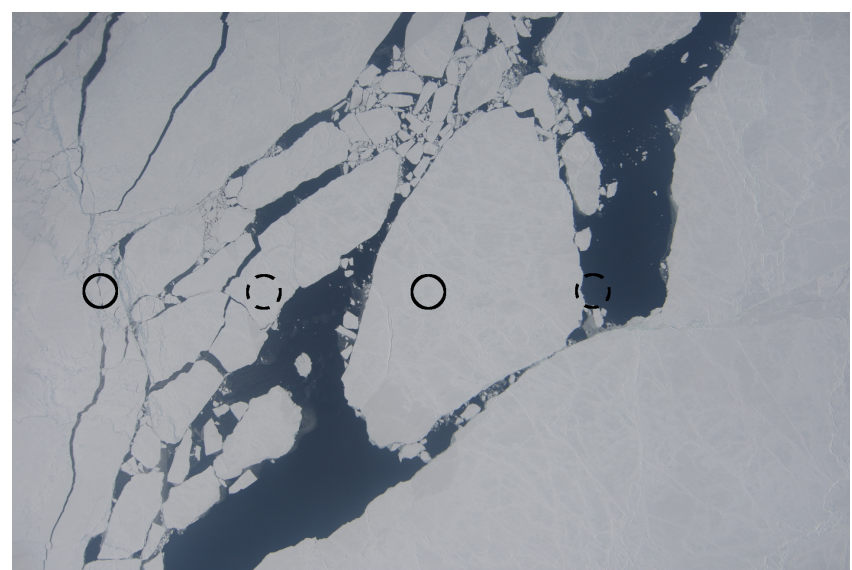

Figure 10. Downward picture of the surface taken on 21 April at 17:35 UTC and $3.8 \mathrm{~km}$ altitude. The $300 \mathrm{~m}$ diameter circles depict the FIRR footprint at the surface for a single $0.8 \mathrm{~s}$ measurement. Plain line circles indicate the relative positions of the aircraft when the measurement is performed on the first filter, and dashed circles when performed on the last filter (flight direction is to the right). It takes approximately $20 \mathrm{~s}$ to measure all nine filters and another $20 \mathrm{~s}$ to come back to the position of the first filter.

(Fig. 11), probably due to radiative cooling at top of the nearsurface cloud. Observed FIRR brightness temperatures are consistent with the atmospheric profile. In the clear sky region, the profiles are similar to that of 11 April. In clouds, brightness temperature varies more rapidly with altitude, as a consequence of increased absorption and scattering in all channels. Consequently, all brightness temperatures samples at $5.7 \mathrm{~km}$ are contained in a narrow $1.5 \mathrm{~K}$ range.

Since CALIPSO does not cover such high latitudes, we do not have supplementary information regarding the clouds properties. The profile of relative humidity suggests that the cloud was initiated above $5 \mathrm{~km}$ in saturated air with respect to ice, and below ice particles were precipitating without saturating the air. For the MODTRAN simulations, the particle effective diameter was set to $75 \mu \mathrm{m}$, with relatively large particles consistently seen by the $2 \mathrm{D}-\mathrm{C}$ probe but missed by the FSSP-300. We then tuned the optical depth to 0.5 for the near-surface cloud layer and 1.0 for the upper layer cloud. This set of cloud properties produces brightness temperatures profiles in agreement with the measurements. The brightness temperature difference between 7.9-9.5 $\mu \mathrm{m}$ and $10-12 \mu \mathrm{m}$ channels is larger in the model than in the observations yet, which suggests an imperfect definition of aerosol and haze profiles.

\subsubsection{April}

The best case of optically thin ice cloud was observed during 13 April flight. A vertical profile was taken during the descent between 18:15 and 19:12 UTC. The temperature profile was fairly typical of Arctic winter conditions, with an
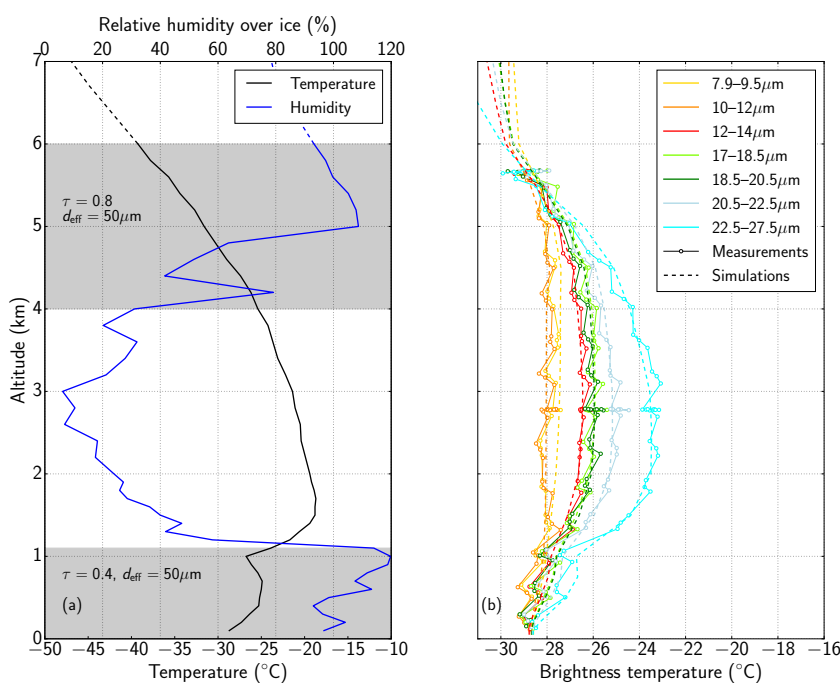

Figure 11. Vertical profiles of (a) temperature and relative humidity and (b) measured and simulated FIRR brightness temperatures for 7 April flight. Shaded areas in panel (a) indicate the presence of clouds. The optical thickness and particle effective diameter used for the simulations are also indicated. The dashed lines correspond to the ERA-Interim profiles used for the simulations above maximum flying altitude.

inversion at $1.3 \mathrm{~km}$ and surface temperature around $-25^{\circ} \mathrm{C}$ (Fig. 12a). A tenuous cloud layer was found below $1 \mathrm{~km}$ and a much thicker cloud was observed between 2.2 and $5 \mathrm{~km}$ according to the combination of 2D-C and FSSP-300 probes. These two instruments, along with the relative humidity profile, suggest that ice particles formed above $3 \mathrm{~km}$ but large precipitating crystals were observed down to $2.2 \mathrm{~km}$. This cloud is similar to a TIC-2B type from the classification of Grenier et al. (2009). The FIRR brightness temperatures are characterized by high vertical variability, especially above $3 \mathrm{~km}$ (Fig. 12b). This variability is identical for all bands, suggesting that it is due to actual scene variations. The excellent match between KT19 measurements and the 10-12 $\mu \mathrm{m}$ channel confirms that observed variations are not instrumental artifacts (Fig. 12c). Instead, they are attributed to cloud horizontal variability. This hypothesis is supported by the sun-photometer data that show highly varying optical depth above the aircraft as well.

Since the aircraft is flying in quasi-spirals of $10 \mathrm{~km}$ diameter, any cloud variability below this scale results in signal variability on the vertical profile. Down-looking pictures taken on Polar 6 show that above $3 \mathrm{~km}$, surface features were intermittently visible, meaning that cloud optical depth varied substantially along the flight path. Attempting to reproduce the measured brightness temperature profiles with a 1-D model was impractical. Instead, several MODTRAN simulations were performed for various optical depths. For these simulations, particle effective diameter was set to $120 \mu \mathrm{m}$, consistently with DARDAR product 

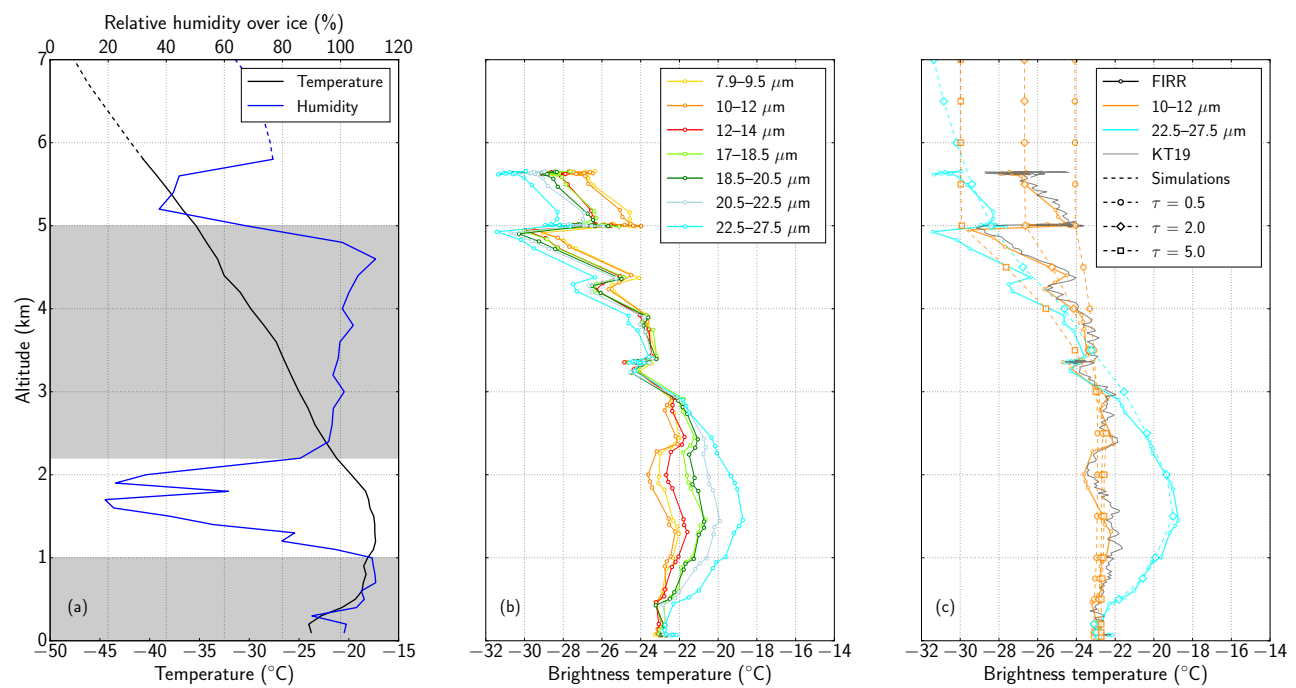

Figure 12. Vertical profiles of (a) temperature and relative humidity and (b) FIRR brightness temperatures for 13 April flight. In panel (a), the shaded areas indicate the presence of clouds and the dashed lines correspond to the ERA-Interim profiles used for the simulations above maximum flying altitude. Panel (c) shows measured and simulated brightness temperatures for two FIRR bands and various optical depths of the upper cloud. KT19 temperatures are shown as well for comparison to FIRR 10-12 $\mu$ m channel.

corresponding to a CALIPSO overpass at 16:10 UTC. The near-surface cloud optical depth was set to 0.07 , while the upper cloud optical depth $\tau$ was varied from 0.5 to 5 in the calculations. Figure $12 \mathrm{c}$ shows that the range $0.5-5$ reproduces quite well the observed variability of brightness temperature. We infer that at small scale cloud variability is extremely high, which is unexpected from satellite data on the large scale for this type of cloud (Grenier et al., 2009). To further investigate the spatial variability, MODIS cloud products at 18:09 UTC were analyzed. In particular, the cloud optical depth and cloud top altitude, shown in Fig. 13, are very instructive. At the scale of Polar 6 spiral, the cloud optical depth is indeed highly variable, ranging from nearly clear sky to values exceeding 5 . The cloud top altitude also shows that the probed cloud with top at $5 \mathrm{~km}$ was very localized in the most southeastern section of the spiral. Interestingly, these spatial features are consistent with FIRR observations. In fact, the difference between the temperature measured by the 10-12 $\mu \mathrm{m}$ channel and the simulation with $\tau=2$ (indicated by the colour of the trajectory in Figs. 13a and $b$ ) is minimum near the area corresponding to the high-altitude cloud, which suggests that the cloud there has an optical depth larger than 2. The difference is larger elsewhere, meaning that FIRR senses warmer temperatures corresponding to either a thinner or lower cloud. The variations of the brightness temperature difference are more evident in Fig. 13c, which shows the time series of the difference along with the MODIS estimates of cloud characteristics. Observed FIRR spatial variability is thus consistent with the presence of a cloud of optical depth around 4 in the southeastern bound of the trajectory that extends up to $5 \mathrm{~km}$. Elsewhere on the trajectory the atmosphere ranges from clear to low-altitude clouds. The latter also seem to be variable, resulting in slight variations of brightness temperature in the window channels near the surface. This case illustrates the complexity of atmospheric radiative transfer in heterogeneous conditions. It also shows that the FIRR is responding consistently with variations in clouds conditions from a nadir view similar to a satellite view.

\section{Discussion}

The five case studies investigated in the previous section provided a valuable insight on FIRR performances from an airborne nadir configuration and on the FIR characteristics of the Arctic atmosphere in clear and cloudy conditions. To further explore the dependence of FIRR measurements on atmospheric profiles, a series of radiative transfer simulations are performed. The results are then discussed in the framework of TICFIRE, with the intent to improve the data quality in future similar airborne campaigns.

\subsection{Sensitivity to temperature, humidity and cloud properties}

In order to extend the interpretation of the data acquired during the NETCARE campaign, the Jacobians of the top of atmosphere (TOA) brightness temperature with respect to temperature and humidity were computed for 11 April simulations (Fig. 14). The Jacobian at a given atmospheric level is the difference in simulated TOA brightness temperature resulting from an increase of $1 \mathrm{~K}$ ( $1 \%$ specific humidity) of the temperature (relative humidity) at this level. The temperature Jacobians show that the $30-50 \mu \mathrm{m}$ channel is mostly sensitive to atmospheric layers below $500 \mathrm{hPa}$ (above $\sim 5 \mathrm{~km}$ ), 

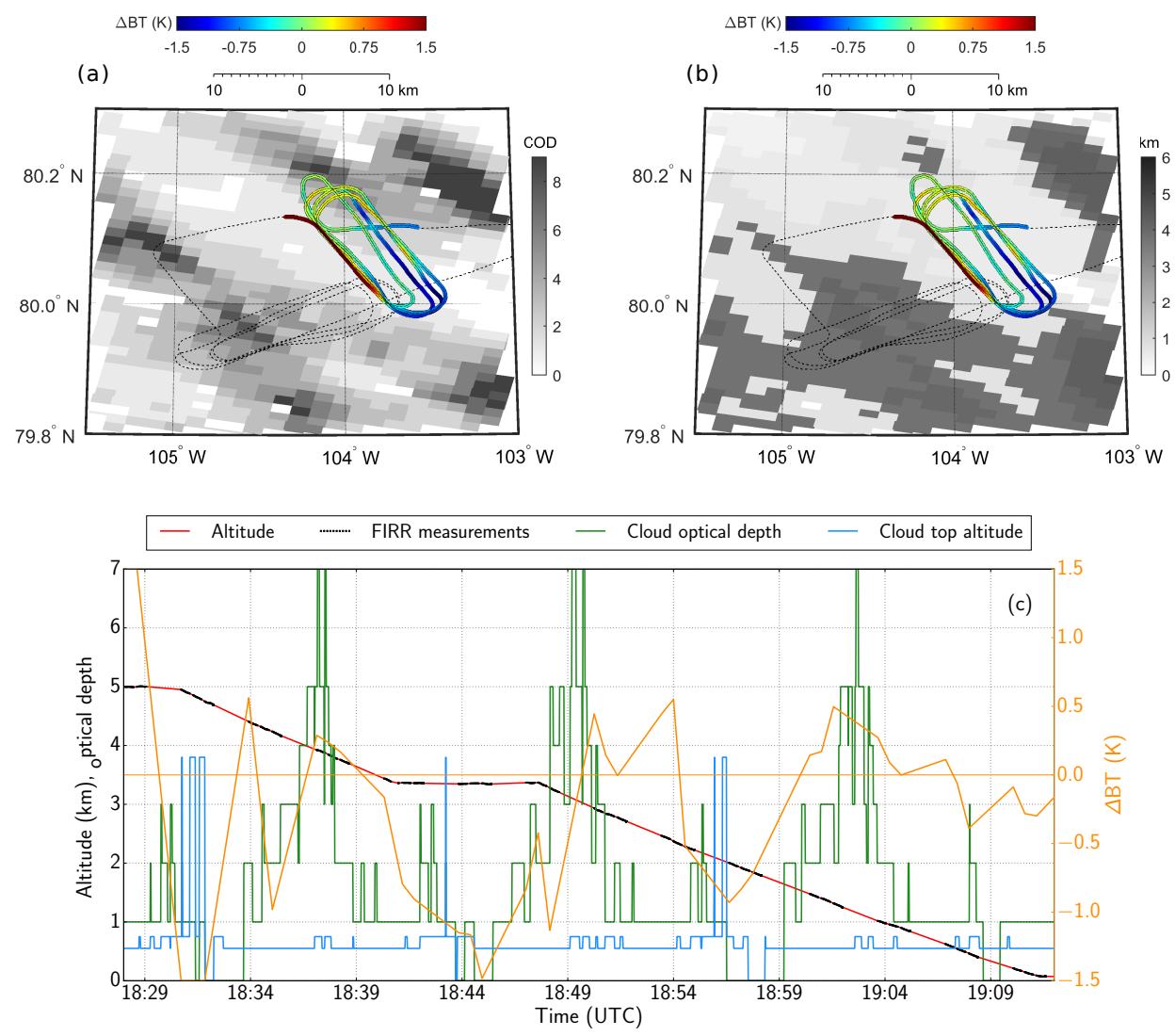

Figure 13. (a) Optical depth at $1.24 \mu \mathrm{m}$ and (b) cloud top altitude derived from MODIS observations at the beginning of the profile on 13 April (18:09 UTC). Polar 6 trajectory is highlighted, with the colour corresponding to the difference between measured and simulated ( $\tau=2$ ) brightness temperatures for the 10-12 $\mu \mathrm{m}$ channel. Blue suggests the actual optical depth is larger than 2 while red suggests it is less. (c) Difference between measured and simulated $(\tau=2)$ brightness temperatures for the $10-12 \mu \mathrm{m}$ channel as a function of time, along with flight altitude and MODIS estimates of cloud optical depth and cloud top altitude. Black dots indicate when FIRR spectral measurements are actually performed.

which explains why this channel was not very useful at lower altitude during the campaign. The shorter FIR wavelengths are sensitive to lower layers of the atmosphere, and window channels are almost insensitive to the atmosphere temperature. These Jacobians also suggest that the three channels between 17 and $20 \mu \mathrm{m}$ are very similar, making them somewhat redundant in such atmospheric conditions. Comparing the absolute values of the Jacobians to the FIRR resolution gives a lower estimate of the vertical resolution the FIRR could reach for profiles retrieval applications. Given the radiometric resolution of the FIRR is about $0.2 \mathrm{~K}$, temperature variations of $0.2 \mathrm{~K}$ are detectable with a vertical resolution of 100 to $200 \mathrm{hPa}$ in FIR bands. Regarding the FIRR sensitivity to variations in relative humidity, Fig. 14b shows that the $30-50 \mu \mathrm{m}$ band is the most sensitive, as expected due to the water vapour absorption spectrum. Humidity variations of $5 \%$ for a $100 \mathrm{hPa}$ thick layer above $600 \mathrm{hPa}$ should produce a detectable signal for all FIR bands, highlighting the potential of the FIRR for probing humidity profiles in such cold and dry conditions. Note that the Jacobians are positive around the temperature inversion, which is a feature typical of polar conditions. Negative values are consistent with the fact that increasing water vapour increases the greenhouse effect due to the atmosphere and hence decreases radiation at TOA.

To complement this sensitivity analysis, an ice cloud was inserted between 2 and $6 \mathrm{~km}$ in the same atmosphere, and the relative humidity with respect to ice was correspondingly set to $100 \%$. Starting from a reference cloud, its optical depth and particle effective diameter were varied. Figure 15 shows that TOA FIR brightness temperatures are very sensitive to cloud optical depth, with variations up to $5 \mathrm{~K}$ between clear sky conditions and $\tau=5$. The FIRR resolution approximately converts into a 0.2 resolution in terms of optical depth. The same exercise with varying optical depth shows that for small particles FIR channels are very sensitive to particle size. However, the sensitivity quickly decreases for larger sizes, which is consistent with the findings of Yang et al. (2003) and Baran (2007), who suggested a sensitivity up to $100 \mu \mathrm{m}$ effective dimensions. This sensitivity is directly 

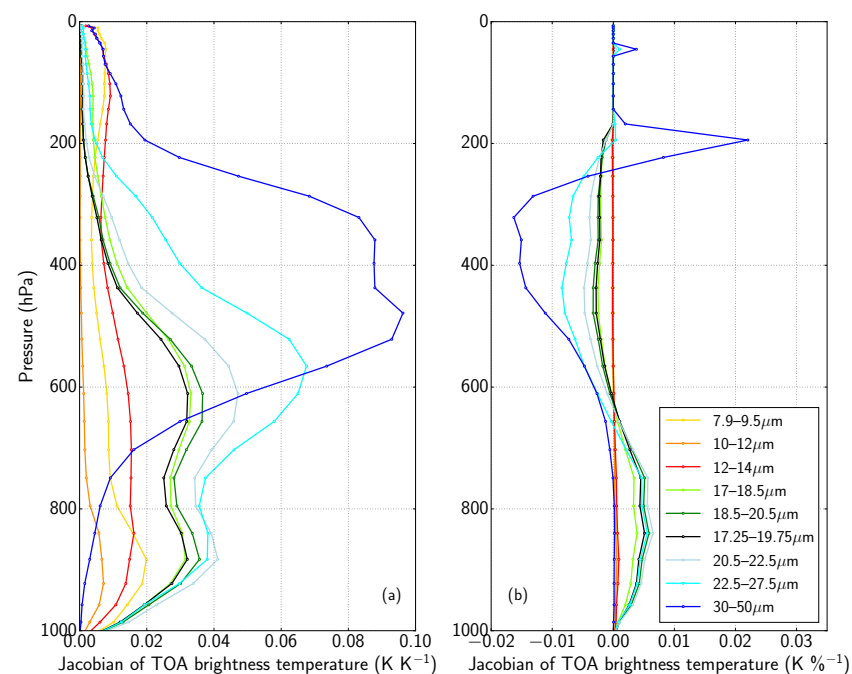

Figure 14. (a) Temperature and (b) humidity Jacobians for the TOA brightness temperature for 11 April atmospheric profile. For humidity, variations are in $\%$ of the specific humidity.

related to the crystal shape and size distribution assumed for this study, which correspond to cirrus clouds. Although the results above are qualitatively robust, using another ice cloud parameterization could have resulted in different values (e.g. Baran, 2007). In particular, Arctic clouds characterized by rapid crystal growth in high supersaturation conditions may actually have shallower particle size distributions (Jouan et al., 2012) and exhibit more sensitivity to particle size.

\subsection{Recommendations for future operation}

The preceding results are now discussed in the framework of planning the TICFIRE satellite mission and in view of future airborne campaigns with the FIRR or similar instruments. First of all, one advantage of using uncooled microbolometers is the possibility to have an imager, as will be the case for TICFIRE. In this study, the FIRR was not used as an imager, though, because it has a much narrower field of view than TICFIRE satellite configuration. However, it is worth exploring how the accuracy of the measurements would decay if spatial averaging were skipped. To this end, the spectral brightness temperature shown in Fig. 7 is computed again from FIRR measurements, except that spatial averaging is made on 1 (no averaging), 4, 9 or 193 pixels. Nominal data processing is optimized for 193 pixels and could not be applied to a single pixel (Libois et al., 2016), so that the procedure was slightly changed to ensure that the same calibration is applied independently of the number of pixels averaged. The results are shown in Fig. 16. As expected, spatial averaging improves the repeatability of the measurement, but averaging over 9 pixels already provides a resolution close to 193 pixels. The absolute values are very consistent, with
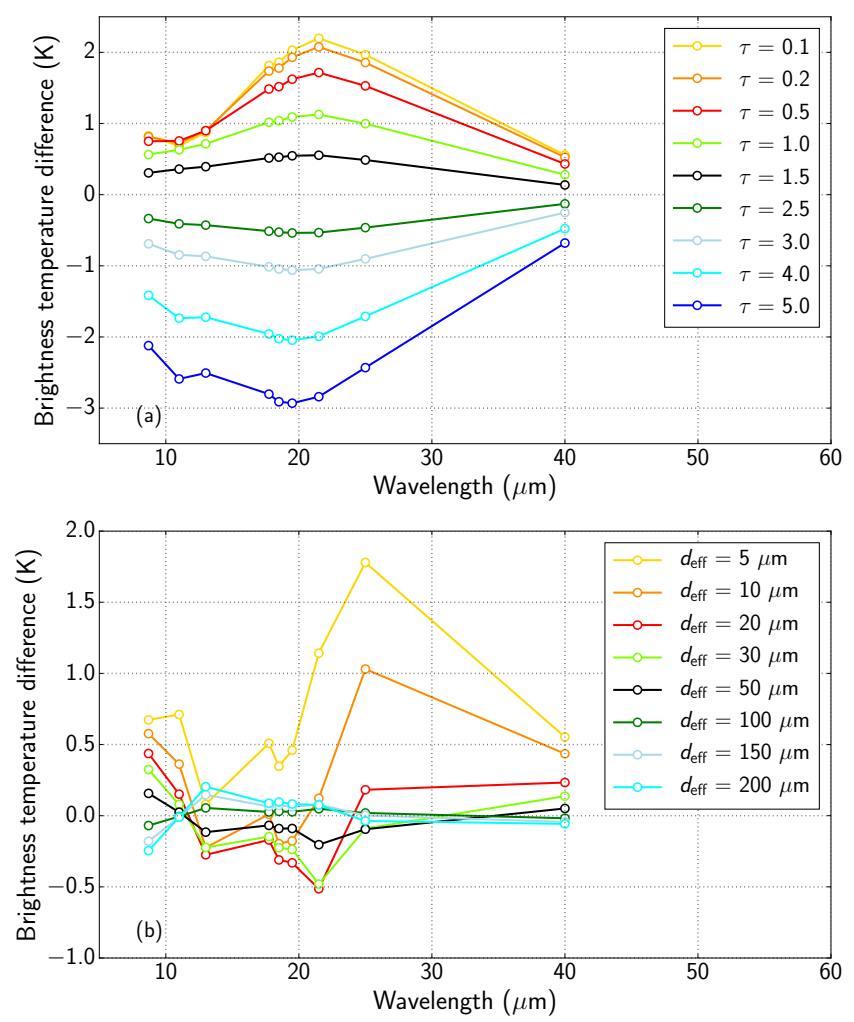

Figure 15. TOA brightness temperature differences between various clouds and the reference with $\tau=2(\tau=3$ for panel $\mathbf{b})$ and $d_{\text {eff }}=80 \mu \mathrm{m}$. Panel (a) is for varying optical depth while panel (b) is for varying particle effective diameter.

differences less than $0.5 \mathrm{~K}$ if more than 1 pixel are used. The remaining differences can be attributed to instrument errors, but scene spatial heterogeneities cannot be ruled out. This suggests that the present study is relevant to verify the performances of the future TICFIRE satellite instrument, the precision of which could be increased through spatial averaging over neighbour pixels.

It is worth pointing out that the NETCARE campaign was not dedicated solely to radiation measurements. Probing ice clouds was one of the objectives, but not the only one. In addition, few clouds were encountered during the campaign and days with too many clouds prevented aircraft operations for safety reasons. Overall the dataset is still modest and further campaigns in the Arctic winter remain necessary, in particular to complete a radiative closure in cloudy conditions, which was not possible here due to lack of quantitative information about clouds properties. Such campaigns should be dedicated to the radiative properties of ice clouds in order to maximize the scientific success of this research topic (e.g. CIRCCREX; Fox, 2015). During the NETCARE campaign, the FIRR was supposed to have a zenith view to allow net fluxes computation and associated cooling rates, but shortly before the campaign started this configuration proved to be incompatible in terms of safety. In the future, com- 


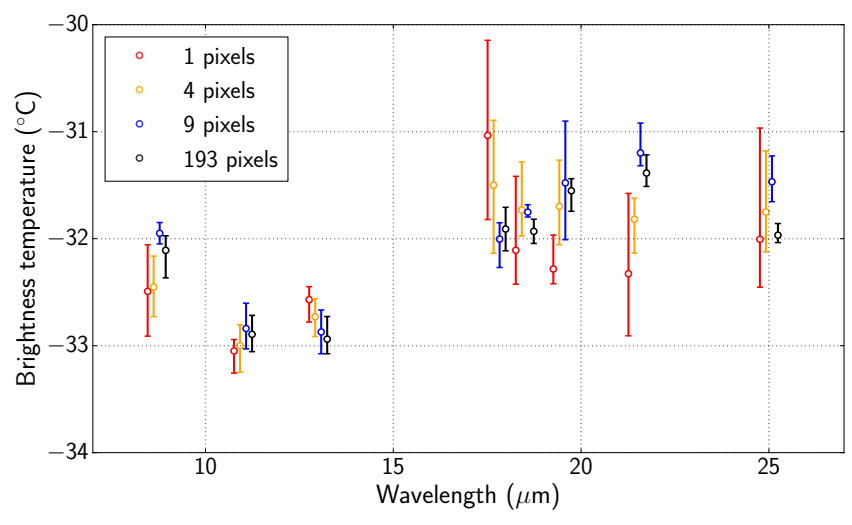

Figure 16. FIRR spectral brightness temperatures at $5.56 \mathrm{~km}$ as in Fig. 7, except that measurements were averaged over a varying number of pixels, from 1 to 193. Error bars indicate measurement variability along four consecutive measurements. For each spectral band the four corresponding error bars are slightly displaced horizontally for sake of clarity.

bining nadir and zenith views as in Mlynczak et al. (2011) would be extremely beneficial to the understanding of the atmospheric radiative budget in the FIR. From the FIRR perspective, we noticed that upgrading the current instrument radiometric resolution is essential to further constrain radiative transfer simulations and cloud properties retrievals. This can be achieved by improving the environmental conditions of the FIRR within the aircraft, paying more attention to temperature stability. Adding an insulating window to prevent air circulation around the instrument or increasing the pressure inside the instrument to ensure constant outflow from the aircraft would minimize temperature variations. Note that these recommendations are linked to the fact that Polar 6 cabin is unpressurized and other constraints should be thought of in the case of a pressurized aircraft. Complementary zenith and nadir observations would also be extremely valuable in order to compute cooling rates and sample the whole atmospheric profile.

At the instrument level, the FIRR is the first prototype and improvements are expected from technological developments of uncooled microbolometers, but optimization in the analogical-numerical converter and absence of the detector window in space could already increase the current resolution by a factor of 3 to 5 . Likewise, increasing acquisition rate by using a faster filter wheel and scene selection motor would reduce the acquisition time of a sequence by one order of magnitude, thus limiting temperature variations in between calibrations. It would also ensure that measurements in all channels are taken on the same target, which was not always the case during the campaign above leads or through highly heterogeneous ice clouds. Such technical developments are already considered and will be mandatory for the satellite version of the instrument which requires acquisition times around $1 \mathrm{~s}$ for a complete scene sequence.

\section{Conclusions}

The first airborne campaign of the FIRR took place in the Arctic in the framework of the NETCARE aircraft campaign. It was a great opportunity to study the radiative properties of the early spring Arctic atmosphere, and it highlighted the importance of water vapour and ice clouds in this remote environment. Vertical profiles of brightness temperature acquired in clear sky and cloudy conditions provided a strong observational constraint on the radiative properties. At the same time, they increased the limited amount of observations available in the far-infrared, especially in such remote regions. These observations also provided valuable knowledge about the FIRR instrument, which can be used to improve operation and development in view of the TICFIRE satellite mission. This campaign showed that the current state-of-the-art radiative transfer models are well suited for the Arctic and confirm that instrument resolution is better than the uncertainties inherent to the radiative transfer formulation and input observations. They also show that aerosols can significantly impact the radiative budget of the atmosphere, thus implying that a detailed characterization of the aerosols and haze is necessary to refine radiative closure experiments. Although the FIRR behaved very well during the campaign with respect to its nominal performances, the latter could be improved for accurate retrievals of atmospheric and cloud characteristics. The campaign proved that ice clouds in the Arctic are hard to probe, as much for reasons of safety as for their complexity and their high heterogeneity. As a consequence, measured ice clouds spectral signature could not be compared to simulations with sufficiently well-constrained cloud properties. Such airborne campaigns should be replicated to improve our understanding of ice cloud formation and radiative properties in polar regions. Accordingly, they should be dedicated to radiation and combine cloud microphysical observations with various radiation sensors. Such studies are necessary to continue improving our knowledge of ice cloud formation and its parameterization in numerical weather prediction and climate models.

\section{Data availability}

All NETCARE data will be made public after the end of the project (http://www.netcare-project.ca). In the meantime, access can be granted by contacting the project manager Bob Christensen (bob.christensen@utoronto.ca). The FIRR data used in this study are available upon request from the authors (quentin.libois@polytechnique.edu). Requests for access to AWI data should be sent to Martin Gehrmann (martin.gehrmann@awi.de). The CALIPSO and DARDAR products were obtained from the ICARE Data Center (http:// www.icare.univ-lille1.fr/). MODIS data were obtained from LAADS (https://ladsweb.nascom.nasa.gov/). 
Author contributions. Q. Libois, L. Ivanescu and H. Schulz operated the FIRR during the airborne campaign. H. Bozem and W. R. Leaitch were scientific leaders aboard Polar 6 and responsible for gas measurements and cloud probes, respectively. J. Burkart and A. A. Aliabadi processed the meteorological and aircraft data. Q. Libois and L. Ivanescu processed the data and Q. Libois performed the radiative transfer simulations. Q. Libois wrote the manuscript with contributions of all co-authors.

Acknowledgements. This research was funded jointly by the Canadian Space Agency (CSA) through the FAST program, by NETCARE through the Climate Change and Atmospheric Research (CCAR) program at the Natural Sciences and Engineering Research Council of Canada (NSERC), by the Alfred Wegener Institute (AWI) and by Environment and Climate Change Canada (ECCC). We are grateful to the editor for his support and acknowledge the two reviewers who helped improve the quality of the manuscript. We thank the Nunavut Research Institute and the Nunavut Impact Review Board for licensing the study. We thank Kenn Borek Air Ltd (KBAL), in particular Gary Murtsell and Neil Travers for their skillful piloting across the Arctic. We acknowledge Martin Gehrmann, Manuel Sellmann and Lukas Kandora (AWI) for their technical help during airborne operation. We thank Alexei Korolev (ECCC) for providing Nevzorov and 2D-C probe data and Gerit Birnbaum (AWI) for helping with the processing of AWI radiation sensors. Norm O'Neill (Université de Sherbrooke) accommodated the involvement of L. Ivanescu to the campaign. Canadian Network for the Detection of Atmospheric Change (CANDAC), to which L. Ivanescu is affiliated, provided logistic support during the stay at Eureka Weather Station. The Institut National d'Optique (INO) provided technical support for the FIRR before and during the campaign. We are grateful to Marcus Dejmek and Daniel Gratton (CSA) for providing logistic resources for the FIRR. We are indebted to Mike Harwood (ECCC) for his direction of the instrument integration and support in the field. We also thank John Ford, David Heath and the University of Toronto machine shop, Jim Hodgson and Lake Central Air Services (LCAS) in Muskoka, Jim Watson (Scale Modelbuilders, Inc.), Andrew Elford (ECCC) and Julia Binder (AWI) for their support of the instrument integration. We are grateful to Bob Christensen (U. Toronto), Doug MacKenzie (KBAL), Rosa Wu, Carrie Taylor, Sangeeta Sharma, Desiree Toom, Dan Veber, Alina Chivulescu, Andrew Platt, Ralf Staebler, Anne Marie Macdonald and Maurice Watt (ECCC) for their support of the study. We acknowledge modelling support from MPIC and University of Mainz, Mainz (Daniel Kunkel, Jens Krause and Franziska Köllner) and University of Québec at Montréal (Ana Cirisan and a class of students) used for flight planning. We thank the Biogeochemistry department of MPIC for providing the CO instrument and Dieter Scharffe for his support during the preparation phase of the campaign.

Edited by: D. J. Cziczo

Reviewed by: two anonymous referees

\section{References}

Aliabadi, A. A., Staebler, R. M., Liu, M., and Herber, A.: Characterization and Parametrization of Reynolds Stress and Turbulent Heat Flux in the Stably-Stratified Lower Arctic Troposphere Using Aircraft Measurements, Bound.-Lay. Meteorol., 161, 99126, doi:10.1007/s10546-016-0164-7, 2016.

Aumann, H., Chahine, M., Gautier, C., Goldberg, M., Kalnay, E., McMillin, L., Revercomb, H., Rosenkranz, P., Smith, W., Staelin, D., Strow, L., and Susskind, J.: AIRS/AMSU/HSB on the aqua mission: design, science objectives, data products, and processing systems, IEEE T. Geosci. Remote, 41, 253-264, doi:10.1109/TGRS.2002.808356, 2003.

Baran, A. J.: The impact of cirrus microphysical and macrophysical properties on upwelling far-infrared spectra, Q. J. Roy. Meteor. Soc., 133, 1425-1437, doi:10.1002/qj.132, 2007.

Berk, A., Anderson, G. P., Acharya, P. K., Bernstein, L. S., Muratov, L., Lee, J., Fox, M., Adler-Golden, S. M., Chetwynd, J. H., Hoke, M. L., Lockwood, R. B., Gardner, J. A., Cooley, T. W., Borel, C. C., and Lewis, P. E.: MODTRAN 5: a reformulated atmospheric band model with auxiliary species and practical multiple scattering options: update, Proc. SPIE 5806, Algorithms and Technologies for Multispectral, Hyperspectral, and Ultraspectral Imagery XI, 662 pp., doi:10.1117/12.606026, 2005.

Bianchini, G., Palchetti, L., Muscari, G., Fiorucci, I., Di Girolamo, P., and Di Iorio, T.: Water vapor sounding with the far infrared REFIR-PAD spectroradiometer from a high-altitude groundbased station during the ECOWAR campaign, J. Geophys. Res., 116, D2, doi:10.1029/2010JD014530, 2011.

Blanchard, Y., Royer, A., O'neill, N. T., and Blanchet, J.P.: Retrieving cloud optical depth and ice particle size using thermal and Far infrered radiometry in an Arctic environment, Geoscience and Remote Sensing Symposium, 2009 IEEE International, IGARSS 2009, III-849-III-852, doi:10.1109/IGARSS.2009.5417902, 2009.

Blanchet, J.-P., Royer, A., Châteauneuf, F., Bouzid, Y., Blanchard, Y., Hamel, J.-F., de Lafontaine, J., Gauthier, P., O’Neill, N. T., Pancrati, O., and Garand, L.: TICFIRE: a far infrared payload to monitor the evolution of thin ice clouds, in: SPIE Remote Sensing. International Society for Optics and Photonics, 81761, 81761K-81761K-11, doi:10.1117/12.898577, 2011.

Blumstein, D., Chalon, G., Carlier, T., Buil, C., Hebert, P., Maciaszek, T., Ponce, G., Phulpin, T., Tournier, B., Simeoni, D., Astruc, P., Clauss, A., Kayal, G., and Jegou, R.: IASI instrument: technical overview and measured performances, in: Optical Science and Technology, the SPIE 49th Annual Meeting. International Society for Optics and Photonics, 196-207, doi:10.1117/12.560907, 2004.

Canas, T. A., Murray, J. E., and Harries, J. E.: Tropospheric airborne Fourier transform spectrometer (TAFTS), in: Aerospace Remote Sensing'97. International Society for Optics and Photonics, 3220, 91-102, doi:10.1117/12.301139, 1997.

Chen, X., Huang, X., and Flanner, M. G.: Sensitivity of modeled far-IR radiation budgets in polar continents to treatments of snow surface and ice cloud radiative properties, Geophys. Res. Lett., 41, 6530-6537, doi:10.1002/2014GL061216, 2014.

Clough, S., Shephard, M., Mlawer, E., Delamere, J., Iacono, M., Cady-Pereira, K., Boukabara, S., and Brown, P.: Atmospheric radiative transfer modeling: a summary of 
the AER codes, J. Quant. Spectrosc. Ra., 91, 233-244, doi:10.1016/j.jqsrt.2004.05.058, 2005.

Clough, S. A., Iacono, M. J., and Moncet, J.-L.: Line-byline calculations of atmospheric fluxes and cooling rates: Application to water vapor, J. Geophys. Res., 97, 15761, doi:10.1029/92JD01419, 1992.

Conrath, B. J., Hanel, R. A., Kunde, V. G., and Prabhakara, C.: The Infrared Interferometer Experiment on Nimbus 3, J. Geophys. Res., 75, 5831-5857, doi:10.1029/JC075i030p05831, 1970.

Cox, C. J., Turner, D. D., Rowe, P. M., Shupe, M. D., and Walden, V. P.: Cloud Microphysical Properties Retrieved from Downwelling Infrared Radiance Measurements Made at Eureka, Nunavut, Canada (2006-09), J. Appl. Meteorol. Clim., 53, 772791, doi:10.1175/JAMC-D-13-0113.1, 2014.

Cox, C. J., Walden, V. P., Rowe, P. M., and Shupe, M. D.: Humidity trends imply increased sensitivity to clouds in a warming Arctic, Nature Communications, 6, 10117, doi:10.1038/ncomms10117, 2015.

Cox, C. V., Harries, J. E., Taylor, J. P., Green, P. D., Baran, A. J., Pickering, J. C., Last, A. E., and Murray, J.: Measurement and simulation of mid- and far-infrared spectra in the presence of cirrus, Q. J. Roy. Meteor. Soc., 136, 718-739, doi:10.1002/qj.596, 2010.

Dee, D. P., Uppala, S. M., Simmons, A. J., Berrisford, P., Poli, P., Kobayashi, S., Andrae, U., Balmaseda, M. A., Balsamo, G., Bauer, P., Bechtold, P., Beljaars, A. C. M., van de Berg, L., Bidlot, J., Bormann, N., Delsol, C., Dragani, R., Fuentes, M., Geer, A. J., Haimberger, L., Healy, S. B., Hersbach, H., Hólm, E. V., Isaksen, L., Kållberg, P., Köhler, M., Matricardi, M., McNally, A. P., Monge-Sanz, B. M., Morcrette, J.-J., Park, B.-K., Peubey, C., de Rosnay, P., Tavolato, C., Thépaut, J.-N., and Vitart, F.: The ERA-Interim reanalysis: configuration and performance of the data assimilation system, Q. J. Roy. Meteor. Soc., 137, 553-597, doi:10.1002/qj.828, 2011

Delamere, J. S., Clough, S. A., Payne, V. H., Mlawer, E. J., Turner, D. D., and Gamache, R. R.: A far-infrared radiative closure study in the Arctic: Application to water vapor, J. Geophys. Res., 115, D17, doi:10.1029/2009JD012968, 2010.

Delanoë, J. and Hogan, R. J.: Combined CloudSat-CALIPSOMODIS retrievals of the properties of ice clouds, J. Geophys. Res., 115, D4, doi:10.1029/2009JD012346, 2010.

Ehrlich, A. and Wendisch, M.: Reconstruction of high-resolution time series from slow-response broadband terrestrial irradiance measurements by deconvolution, Atmos. Meas. Tech., 8, 36713684, doi:10.5194/amt-8-3671-2015, 2015.

Emery, W. J., Good, W. S., Tandy, W., Izaguirre, M. A., and Minnett, P. J.: A Microbolometer Airborne Calibrated Infrared Radiometer: The Ball Experimental Sea Surface Temperature (BESST) Radiometer, IEEE T. Geosci. Remote, 52, 7775-7781, doi:10.1109/TGRS.2014.2318683, 2014.

Feldman, D. R., Collins, W. D., Pincus, R., Huang, X., and Chen, X.: Far-infrared surface emissivity and climate, P. Natl. Acad. Sci. USA, 111, 16297-16302, doi:10.1073/pnas.1413640111, 2014.

Fox, C.: Far-infrared spectral radiance studies: Application to water vapour and cirrus, $\mathrm{PhD}$ thesis, 2015.

Fox, C., Green, P. D., Pickering, J. C., and Humpage, N.: Analysis of far-infrared spectral radiance observations of the water vapor continuum in the Arctic, J. Quant. Spectrosc. Ra., 155, 57-65, doi:10.1016/j.jqsrt.2015.01.001, 2015.

Garand, L., Turner, D. S., Larocque, M., Bates, J., Boukabara, S. Brunel, P., Chevallier, F., Deblonde, G., Engelen, R., Hollingshead, M., Jackson, D., Jedlovec, G., Joiner, J., Kleespies, T., McKague, D. S., McMillin, L., Moncet, J.-L., Pardo, J. R., Rayer, P. J., Salathe, E., Saunders, R., Scott, N. A., Van Delst, P., and Woolf, H.: Radiance and Jacobian intercomparison of radiative transfer models applied to HIRS and AMSU channels, J. Geophys. Res.-Atmos., 106, 24017-24031, doi:10.1029/2000JD000184, 2001

Green, P. D., Newman, S. M., Beeby, R. J., Murray, J. E., Pickering, J. C., and Harries, J. E.: Recent advances in measurement of the water vapour continuum in the far-infrared spectral region, Philosophical Transactions of the Royal Society A: Mathematical, Phys. Eng. Sci., 370, 2637-2655, doi:10.1098/rsta.2011.0263, 2012.

Grenier, P., Blanchet, J., and Munoz-Alpizar, R.: Study of polar thin ice clouds and aerosols seen by CloudSat and CALIPSO during midwinter 2007, J. Geophys. Res., 114, D9, doi:10.1029/2008JD010927, 2009.

Harries, J., Carli, B., Rizzi, R., Serio, C., Mlynczak, M., Palchetti, L., Maestri, T., Brindley, H., and Masiello, G.: The Far-infrared Earth, Rev. Geophys., 46, doi:10.1029/2007RG000233, 2008.

Huang, Y., Leroy, S., Gero, P. J., Dykema, J., and Anderson, J.: Separation of longwave climate feedbacks from spectral observations, J. Geophys. Res., 115, D7, doi:10.1029/2009JD012766, 2010.

Jouan, C., Girard, E., Pelon, J., Gultepe, I., Delanoë, J., and Blanchet, J.-P.: Characterization of Arctic ice cloud properties observed during ISDAC, J. Geophys. Res., 117, D23, doi:10.1029/2012JD017889, 2012.

King, M., Menzel, W., Kaufman, Y., Tanre, D., Bo-Cai Gao, Platnick, S., Ackerman, S., Remer, L., Pincus, R., and Hubanks, P.: Cloud and aerosol properties, precipitable water, and profiles of temperature and water vapor from MODIS, IEEE T. Geosci., 41, 442-458, doi:10.1109/TGRS.2002.808226, 2003.

Knuteson, R. O., Revercomb, H. E., Best, F. A., Ciganovich, N. C., Dedecker, R. G., Dirkx, T. P., Ellington, S. C., Feltz, W. F., Garcia, R. K., Howell, H. B., Smith, W. L., Short, J. F., and Tobin, D. C.: Atmospheric Emitted Radiance Interferometer. Part I: Instrument Design, J. Atmos. Ocean. Tech., 21, 1763-1776, doi:10.1175/JTECH-1662.1, 2004.

Korolev, A. V., Strapp, J. W., Isaac, G. A., and Nevzorov, A. N.: The Nevzorov Airborne Hot-Wire LWC-TWC Probe: Principle of Operation and Performance Characteristics, J. Atmos. Ocean. Tech., 15, 1495-1510, doi:10.1175/15200426(1998)015<1495:TNAHWL>2.0.CO;2, 1998.

Leaitch, W. R., Korolev, A., Aliabadi, A. A., Burkart, J., Willis, M. D., Abbatt, J. P. D., Bozem, H., Hoor, P., Köllner, F., Schneider, J., Herber, A., Konrad, C., and Brauner, R.: Effects of 20$100 \mathrm{~nm}$ particles on liquid clouds in the clean summertime Arctic, Atmos. Chem. Phys., 16, 11107-11124, doi:10.5194/acp-1611107-2016, 2016.

Libois, Q., Proulx, C., Ivanescu, L., Coursol, L., Pelletier, L. S., Bouzid, Y., Barbero, F., Girard, É., and Blanchet, J.-P.: A microbolometer-based far infrared radiometer to study thin ice clouds in the Arctic, Atmos. Meas. Tech., 9, 1817-1832, doi:10.5194/amt-9-1817-2016, 2016 
Liuzzi, G., Masiello, G., Serio, C., Palchetti, L., and Bianchini, G.: Validation of $\mathrm{H}_{2} \mathrm{O}$ Continuum Absorption Models in the Wave Number Range $180-600 \mathrm{~cm}^{-1}$ with Atmospheric Emitted Spectral Radiance Measured at the Antarctica Dome-C Site, Opt. Express, 22, 16784, doi:10.1364/OE.22.016784, 2014.

Maestri, T.: A study of infrared diabatic forcing of ice clouds in the tropical atmosphere, J. Geophys. Res., 108, D4, doi:10.1029/2002JD002146, 2003.

Maestri, T., Rizzi, R., and Smith, J. A.: Spectral infrared analysis of a cirrus cloud based on Airborne Research Interferometer Evaluation System (ARIES) measurements, J. Geophys. Res.-Atmos., 110, D6, doi:10.1029/2004JD005098, 2005.

Maestri, T., Rizzi, R., Tosi, E., Veglio, P., Palchetti, L., Bianchini, G., Di Girolamo, P., Masiello, G., Serio, C., and Summa, D.: Analysis of cirrus cloud spectral signatures in the far infrared, J. Quant. Spectrosc. Ra., 141, 49-64, doi:10.1016/j.jqsrt.2014.02.030, 2014.

Mariani, Z., Strong, K., Wolff, M., Rowe, P., Walden, V., Fogal, P. F., Duck, T., Lesins, G., Turner, D. S., Cox, C., Eloranta, E., Drummond, J. R., Roy, C., Turner, D. D., Hudak, D., and Lindenmaier, I. A.: Infrared measurements in the Arctic using two Atmospheric Emitted Radiance Interferometers, Atmos. Meas. Tech., 5, 329-344, doi:10.5194/amt-5-329-2012, 2012.

Marty, C.: Downward longwave irradiance uncertainty under arctic atmospheres: Measurements and modeling, J. Geophys. Res., 108, D12, doi:10.1029/2002JD002937, 2003.

McCleese, D. J., Schofield, J. T., Taylor, F. W., Calcutt, S. B., Foote, M. C., Kass, D. M., Leovy, C. B., Paige, D. A., Read, P. L., and Zurek, R. W.: Mars Climate Sounder: An investigation of thermal and water vapor structure, dust and condensate distributions in the atmosphere, and energy balance of the polar regions, J. Geophys. Res., 112, E5, doi:10.1029/2006JE002790, 2007.

Merrelli, A. and Turner, D. D.: Comparing Information Content of Upwelling Far-Infrared and Midinfrared Radiance Spectra for Clear Atmosphere Profiling, J. Atmos. Ocean. Tech., 29, 510526, doi:10.1175/JTECH-D-11-00113.1, 2012.

Mlawer, E. J., Payne, V. H., Moncet, J.-L., Delamere, J. S., Alvarado, M. J., and Tobin, D. C.: Development and recent evaluation of the MT_CKD model of continuum absorption, Philosophical Transactions of the Royal Society A: Mathematical, Phys. Eng. Sci., 370, 2520-2556, doi:10.1098/rsta.2011.0295, 2012.

Mlynczak, M., Johnson, D. G., and Cageao, R. P.: Scientific Results from the FIRST Instrument Deployment to Cerro Toco, Chile and from the Flight of the INFLAME Instrument, p. HMB1, OSA, doi:10.1364/HISE.2011.HMB1, 2011.

Mlynczak, M. G., Harries, J. E., Rizzi, R., Stackhouse, P. W., Kratz, D. P., Johnson, D. G., Mertens, C. J., Garcia, R. R., and Soden, B. J.: Far-infrared: a frontier in remote sensing of Earth's climate and energy balance, in: International Symposium on Optical Science and Technology. International Society for Optics and Photonics, 4485, 150-158, doi:10.1117/12.454247, 2002.

Mlynczak, M. G., Johnson, D. G., Latvakoski, H., Jucks, K., Watson, M., Kratz, D. P., Bingham, G., Traub, W. A., Wellard, S. J., Hyde, C. R., and Liu, X.: First light from the Far-Infrared Spectroscopy of the Troposphere (FIRST) instrument, Geophys. Res. Lett., 33, 7, doi:10.1029/2005GL025114, 2006.

Mlynczak, M. G., Cageao, R. P., Mast, J. C., Kratz, D. P., Latvakoski, H., and Johnson, D. G.: Observations of downwelling far-infrared emission at Table Mountain California made by the FIRST instrument, J. Quant. Spectrosc. Ra., 170, 90-105, doi:10.1016/j.jqsrt.2015.10.017, 2016.

Ngo Phong, L., Proulx, C., Oulachgar, H., and Châteauneuf, F.: Far infrared microbolometers for radiometric measurements of ice cloud, in: SPIE OPTO. International Society for Optics and Photonics, 9375 pp., 93750G-93750G-11, 93750G, doi:10.1117/12.2076219, 2015.

O’Neill, N. T., Eck, T. F., Smirnov, A., Holben, B. N., and Thulasiraman, S.: Spectral discrimination of coarse and fine mode optical depth, J. Geophys. Res.-Atmos., 108, D17, doi:10.1029/2002JD002975, 2003.

Paige, D. A., Foote, M. C., Greenhagen, B. T., Schofield, J. T., Calcutt, S., Vasavada, A. R., Preston, D. J., Taylor, F. W., Allen, C. C., Snook, K. J., Jakosky, B. M., Murray, B. C., Soderblom, L. A., Jau, B., Loring, S., Bulharowski, J., Bowles, N. E., Thomas, I. R., Sullivan, M. T., Avis, C., De Jong, E. M., Hartford, W., and McCleese, D. J.: The Lunar Reconnaissance Orbiter Diviner Lunar Radiometer Experiment, Space Sci. Rev., 150, 125160, doi:10.1007/s11214-009-9529-2, 2010.

Palchetti, L., Barbis, A., Harries, J., and Lastrucci, D.: Design and mathematical modelling of the space-borne far-infrared Fourier transform spectrometer for REFIR experiment, Infrared Phys. Techn., 40, 367-377, doi:10.1016/S1350-4495(99)000262, 1999.

Palchetti, L., Belotti, C., Bianchini, G., Castagnoli, F., Carli, B., Cortesi, U., Pellegrini, M., Camy-Peyret, C., Jeseck, P., and Té, Y.: Technical note: First spectral measurement of the Earth's upwelling emission using an uncooled wideband Fourier transform spectrometer, Atmos. Chem. Phys., 6, 5025-5030, doi:10.5194/acp-6-5025-2006, 2006.

Palchetti, L., Bianchini, G., Di Natale, G., and Del Guasta, M.: Far infrared radiative properties of water vapor and clouds in Antarctica, B. Am. Meteorol. Soc., 96, 1505-1518, doi:10.1175/BAMS-D-13-00286.1, 2015.

Palchetti, L., Di Natale, G., and Bianchini, G.: Remote sensing of cirrus cloud microphysical properties using spectral measurements over the full range of their thermal emission: CIRRUS CLOUD FAR IR SIGNATURE, J. Geophys. Res.-Atmos., 121, 10804-10819, doi:10.1002/2016JD025162, 2016.

Platnick, S., King, M., Ackerman, S., Menzel, W., Baum, B., Riedi, J., and Frey, R.: The MODIS cloud products: algorithms and examples from terra, IEEE T. Geosci. Remote, 41, 459-473, doi:10.1109/TGRS.2002.808301, 2003.

Rathke, C.: Improving IR cloud phase determination with 20 microns spectral observations, Geophys. Res. Lett., 29, 8, doi:10.1029/2001GL014594, 2002.

Ritter, C., Notholt, J., Fischer, J., and Rathke, C.: Direct thermal radiative forcing of tropospheric aerosol in the Arctic measured by ground based infrared spectrometry, Geophys. Res. Lett., 32, 23, doi:10.1029/2005GL024331, 2005.

Rizzi, R., Serio, C., and Amorati, R.: Sensitivity of broadband and spectral measurements of outgoing radiance to changes in water vapor content, 181-190, doi:10.1117/12.454250, 2002.

Sauvage, L., Flamant, P. H., Chepfer, H., Brogniez, G., Trouillet, V., Pelon, J., and Albers, F.: Remote Sensing of Cirrus Radiative Parameters during EUCREX'94. Case Study of 17 April 1994. Part I: Observations, Mon. Weather Rev., 127, 486-503, doi:10.1175/1520-0493(1999)127<0486:RSOCRP>2.0.CO;2, 1999. 
Schwarz, J. P., Gao, R. S., Fahey, D. W., Thomson, D. S., Watts, L. A., Wilson, J. C., Reeves, J. M., Darbeheshti, M., Baumgardner, D. G., Kok, G. L., Chung, S. H., Schulz, M., Hendricks, J., Lauer, A., Kärcher, B., Slowik, J. G., Rosenlof, K. H., Thompson, T. L., Langford, A. O., Loewenstein, M., and Aikin, K. C.: Single-particle measurements of midlatitude black carbon and light-scattering aerosols from the boundary layer to the lower stratosphere, J. Geophys. Res., 111, D16, doi:10.1029/2006JD007076, 2006.

Shahabadi, M. B. and Huang, Y.: Measuring Stratospheric $\mathrm{H}_{2}$ $\mathrm{O}$ with an Airborne Spectrometer, J. Atmos. Ocean. Tech., 31, 1502-1515, doi:10.1175/JTECH-D-13-00191.1, 2014.

Shine, K. P., Ptashnik, I. V., and Rädel, G.: The Water Vapour Continuum: Brief History and Recent Developments, Surv. Geophys., 33, 535-555, doi:10.1007/s10712-011-9170-y, 2012.

Shupe, M. D., Matrosov, S. Y., and Uttal, T.: Arctic MixedPhase Cloud Properties Derived from Surface-Based Sensors at SHEBA, J. Atmos. Sci., 63, 697-711, doi:10.1175/JAS3659.1, 2006.

Shupe, M. D., Turner, D. D., Walden, V. P., Bennartz, R., Cadeddu, M. P., Castellani, B. B., Cox, C. J., Hudak, D. R., Kulie, M. S., Miller, N. B., Neely, R. R., Neff, W. D., and Rowe, P. M.: High and Dry: New Observations of Tropospheric and Cloud Properties above the Greenland Ice Sheet, B. Am. Meteorol. Soc., 94, 169-186, doi:10.1175/BAMS-D-11-00249.1, 2013.

Stamnes, K., Tsay, S.-C., Wiscombe, W., and Jayaweera, K.: Numerically stable algorithm for discrete-ordinate-method radiative transfer in multiple scattering and emitting layered media, Appl. Optics, 27, 2502-2509, doi:10.1364/AO.27.002502, 1988.

Stephens, G. L., Vane, D. G., Boain, R. J., Mace, G. G., Sassen, K., Wang, Z., Illingworth, A. J., O'Connor, E. J., Rossow, W. B., Durden, S. L., Miller, S. D., Austin, R. T., Benedetti, A., Mitrescu, C., and CloudSat Science Team, T.: THE CLOUDSAT MISSION AND THE A-TRAIN: A New Dimension of SpaceBased Observations of Clouds and Precipitation, B. Am. Meteorol. Soc., 83, 1771-1790, doi:10.1175/BAMS-83-12-1771, 2002.

Ström, J., Seifert, M., Kärcher, B., Ovarlez, J., Minikin, A., Gayet, J.-F., Krejci, R., Petzold, A., Auriol, F., Haag, W., Busen, R., Schumann, U., and Hansson, H. C.: Cirrus cloud occurrence as function of ambient relative humidity: a comparison of observations obtained during the INCA experiment, Atmos. Chem. Phys., 3, 1807-1816, doi:10.5194/acp-3-1807-2003, 2003.

Susskind, J., Barnet, C., and Blaisdell, J.: Retrieval of atmospheric and surface parameters from AIRS/AMSU/HSB data in the presence of clouds, IEEE T. Geosci. Remote, 41, 390-409, doi:10.1109/TGRS.2002.808236, 2003.
Turner, D. D. and Löhnert, U.: Information Content and Uncertainties in Thermodynamic Profiles and Liquid Cloud Properties Retrieved from the Ground-Based Atmospheric Emitted Radiance Interferometer (AERI), J. Appl. Meteorol. Clim., 53, 752-771, doi:10.1175/JAMC-D-13-0126.1, 2014.

Turner, D. D. and Mlawer, E. J.: The Radiative Heating in Underexplored Bands Campaigns, B. Am. Meteorol. Soc., 91, 911-923, doi:10.1175/2010BAMS2904.1, 2010.

Turner, D. D., Merrelli, A., Vimont, D., and Mlawer, E. J.: Impact of modifying the longwave water vapor continuum absorption model on community Earth system model simulations, J. Geophys. Res., 117, D4, doi:10.1029/2011JD016440, 2012.

Wielicki, B. A., Young, D. F., Mlynczak, M. G., Thome, K. J., Leroy, S., Corliss, J., Anderson, J. G., Ao, C. O., Bantges, R., Best, F., Bowman, K., Brindley, H., Butler, J. J., Collins, W., Dykema, J. A., Doelling, D. R., Feldman, D. R., Fox, N., Huang, X., Holz, R., Huang, Y., Jin, Z., Jennings, D., Johnson, D. G., Jucks, K., Kato, S., Kirk-Davidoff, D. B., Knuteson, R., Kopp, G., Kratz, D. P., Liu, X., Lukashin, C., Mannucci, A. J., Phojanamongkolkij, N., Pilewskie, P., Ramaswamy, V., Revercomb, H., Rice, J., Roberts, Y., Roithmayr, C. M., Rose, F., Sandford, S., Shirley, E. L., Smith, W. L., Soden, B., Speth, P. W., Sun, W., Taylor, P. C., Tobin, D., and Xiong, X.: Achieving Climate Change Absolute Accuracy in Orbit, B. Am. Meteorol. Soc., 94, 1519-1539, doi:10.1175/BAMS-D-12-00149.1, 2013.

Winker, D. M., Pelon, J. R., and McCormick, M. P.: The CALIPSO mission: spaceborne lidar for observation of aerosols and clouds, Proc. SPIE 4893, Lidar Remote Sensing for Industry and Environment Monitoring III, 1, 1-11, doi:10.1117/12.466539, 2003.

Yang, P., Mlynczak, M. G., Wei, H., Kratz, D. P., Baum, B. A., Hu, Y. X., Wiscombe, W. J., Heidinger, A., and Mishchenko, M.: Spectral signature of ice clouds in the far-infrared region: Single-scattering calculations and radiative sensitivity study, J. Geophys. Res., 108, D18, doi:10.1029/2002JD003291, 2003.

Yang, P., Wei, H., Huang, H.-L., Baum, B. A., Hu, Y. X., Kattawar, G. W., Mishchenko, M. I., and Fu, Q.: Scattering and absorption property database for nonspherical ice particles in the near- through far-infrared spectral region, Appl. Optics, 44, 5512, doi:10.1364/AO.44.005512, 2005. 